\title{
On the Potential Value of Interval Deficient Wind Data ${ }^{a}$
}

\author{
E Bernard J Siepker ${ }^{\mathrm{b}}$ and Thomas $\mathrm{M} \mathrm{Harms}^{\mathrm{c}}$
}

\begin{abstract}
The stringent requirements of standards for wind measurements such as IEC 61400-12$1: 2005$ (E) suggest that wind data produced by systems and procedures that do not comply with these standards are deficient and therefore not of sufficient quality for use in wind energy applications. In particular, the standard implies that data are deficient if acquired either intermittently, or continuously - but at averaging intervals exceeding the specified requirements. In order to demonstrate that certain deficient data may in fact be useful in wind energy applications, sets of interval deficient wind data of varying lengths of intermittency - and averaging interval are synthesized from ideal quality data sets produced by systems that closely comply with IEC 61400-12-1:2005(E). Weibull parameters are identified for the data sets and compared. It is inter alia shown that parameters identified from annual sets of wind data acquired at four widely dispersed compliant measurement stations in Southern Africa are remarkably insensitive to the length of intermittency interval and that the parameters can be identified with a relative error of $1 \%$ or better for intermittency intervals of up to 1 hour or longer. This finding suggests that data sets acquired via historic wind measurement devices may indeed be valuable.
\end{abstract}

\section{Keywords}

Wind measurement, Southern Africa, Interval deficient wind data, Weibull parameters

\section{Introduction}

The IEC 61400-12-1:2005(E) standard (1) of the International Electrotechnical Commission describes the requirements for wind measurements as it applies to the power performance evaluation of installed electricity producing wind turbines. Full compliance with this standard is also required for wind resource assessments that are specifically undertaken to provide accurate resource input data for bankable wind projects at particular sites. The standard is not strictly applicable to general wind resource assessments, but it is also often adopted for this purpose. A fundamental requirement of the standard is that wind speed data shall be acquired continuously by a digital data acquisition system (DAS) at a sampling rate of at least $1 \mathrm{~Hz}$ and that means -, standard deviations -, minima - and maxima shall be derived from contiguous samples for each 10 minute period (1 minute for the evaluation of small turbines) and then stored by the DAS. The standard further requires that wind speed inputs to the DAS shall be provided by calibrated electronic (implied) cup anemometers of known classification that are mounted at prescribed elevations relative to the hub height of the tested turbine and at prescribed locations relative to supporting structures and obstacles on the ground in order to avoid excessive interference of these objects with the free stream wind flow onto the sensors.

Wind data not acquired thus are ostensibly deficient and not of sufficient quality for use in wind energy applications. In sequence of most - to least severe in respect of nonadherence to the indicated requirements, examples of deficient data are those that are acquired :

- intermittently via mechanical anemometers and human interaction

- continuously via mechanical anemometers and human interaction

- continuously via electronic DAS served by anemometers other than the cup type and at averaging intervals exceeding those specified by the standard 
- continuously via electronic DAS served by calibrated - and classified cup anemometers at the required sampling rate, but with the anemometers not mounted as specified in the standard.

Intermittent data include manual spot observations of the outputs of mechanical wind pressure sensing devices such as plate wind indicators and Dines anemometers, as well as spot evaluations of the slopes of the traces of mechanical autographic wind recorders. Fig. 1 shows a pressure plate wind indicator that was installed at the Gobabeb Research and Training Centre (GRTC), Gobabeb, Namibia in September 1962. The device is presently still used for synoptic wind observations and the output of the device is observed and recorded three times per day at 06h00, $12 \mathrm{~h} 00$ and 18h00 Universal Co-ordinated Time (UTC).

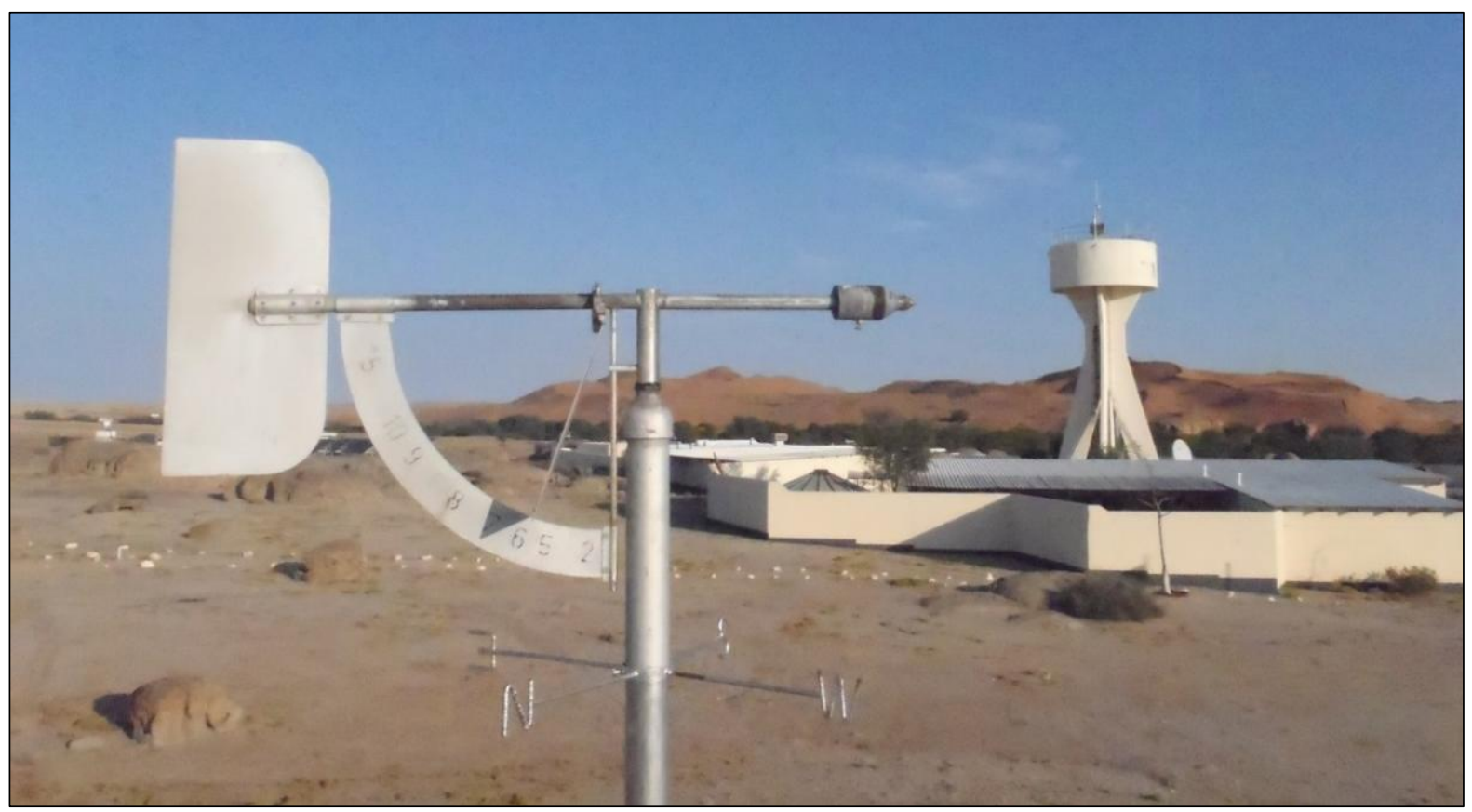

Fig. 1. Pressure plate wind indicator at Gobabeb ${ }^{1}$

Long averaging intervals are associated with integrating devices such as mechanical wind totalizers of which the counter reading is observed once - or only a few times per day, as well as automatic weather stations (AWS) of which the averaging interval is typically set to one hour. Fig. 2 shows a mechanical wind totalizer similar to the device that was first installed at GRTC in October 1962. This type of device is presently still in use for evaporation-related wind observations at Gobabeb. The counter is read once per day at 06h00 UTC. In Namibia, the mentioned mechanical devices had been in extensive use by Namibia Meteorological Services (NMS) and its pre-independence South African predecessors as from the 1940s until the early 1990s when NMS commenced with the augmentation/replacement of the small network of these devices by a larger network of electronic AWS. Unfortunately, however, the data recovery rates (DRR) rendered by the new AWS network proved dismal in comparison to that of the old network, with the consequence that there is a lack of complete sets of compliant - or good quality long term wind data produced by NMS for the period since the independence of Namibia in 1990 to date.

${ }^{1}$ Photo courtesy Mr Titus Shuuya (GRTC) 


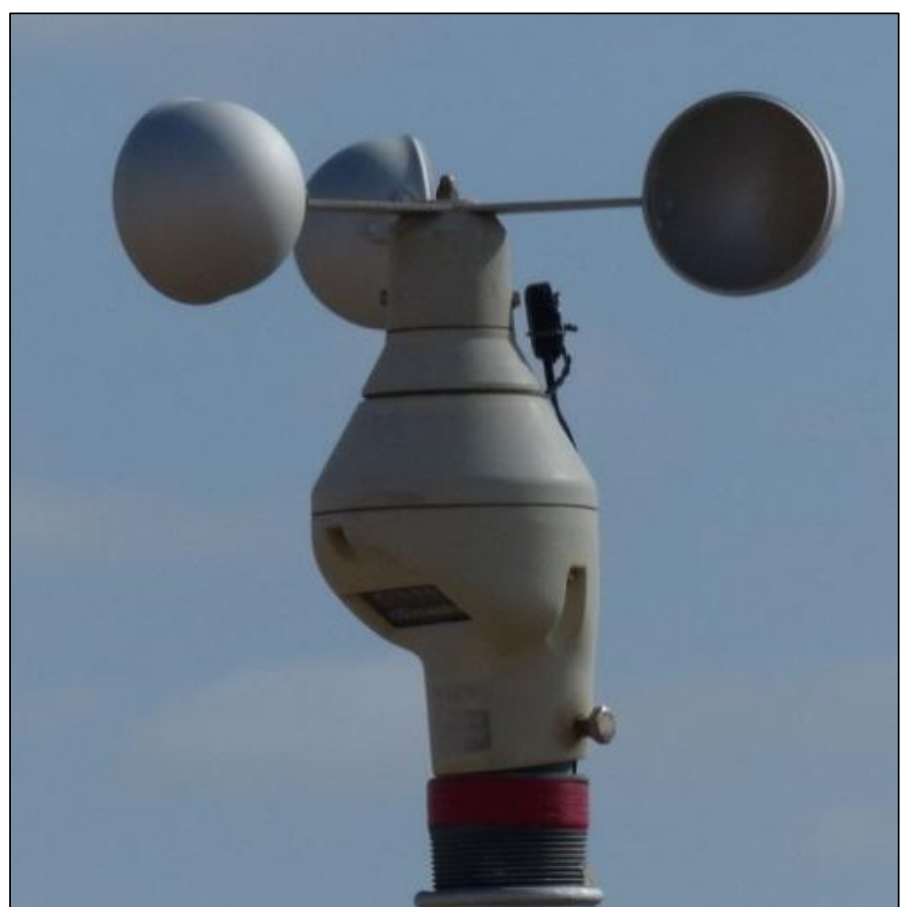

Fig. 2. Mechanical wind totalizer at Gobabeb ${ }^{2}$

The objective of the study of which the results are presented herein is to address this predicament through an empirical investigation into how interval deficiencies influence the extent to which data produced by historic devices can potentially be used to identify accurate Weibull parameters for the wind resources of Namibia in the absence of long term compliant data. Sets of interval deficient wind data of varying lengths of intermittency - and averaging interval are synthesized from ideal quality annual wind data sets produced by DAS that closely comply with IEC 61400-12-1:2005(E) (1). The synthesized deficient data simulate the data produced by the mentioned historic devices. Weibull parameters are identified for all the data sets and the parameters identified from the deficient data compared with those identified from the ideal data which are employed as reference values. Derived Weibull parameters and - mean wind power density are employed in the comparison rather than the measured mean wind power density, because the former can be extrapolated to higher elevations as described by amongst others Kelly et al. (2) and Doran and Verholek (3) who derived equations for the height variation of wind statistics.

No evidence could be found in literature of previous investigations into the sensitivity of annual Weibull parameters on varying lengths of intermittency - and averaging interval. Abbes et al. (4) employed one-minute means of wind data for three stations in the United States of America to synthesize deficient data sets with intermittency intervals ranging between 2 minutes and 4 hours. They investigated the sensitivity of the monthly electrical energy output of a wind turbine on the varying intermittency intervals and found that the outputs associated with longer intermittency intervals are less than predicted by the compliant one-minute means, the difference being less than $10 \%$ for intermittency intervals of up to one hour in all cases.

Ramírez and Carta (5) identified Weibull parameters from a single reduced data set of which the number of data records (300) was calculated on the basis of eliminating to a selected level of significance the auto-correlations in the original data set of 52580 data records. Using Maximum Likelihood estimation to identify the Weibull parameters from the reduced - and original data sets, they found that although the expected values of the Weibull scale parameter derived from the two data sets are virtually the same, there is considerable

${ }^{2}$ Photo courtesy Dr Roland Vogt (University of Basel) 
difference in the expected values of the Weibull shape parameter. They also found that the standard errors for the parameters identified from the reduced data set are an order of magnitude larger than those derived from the auto-correlated data of the original data set. A slightly smaller - but comparable value of the ratio of standard errors in the mean wind speed was found by Brett and Tuller (6) who estimated the parameters of auto-correlation functions for seven stations in Canada.

Employing autocorrelation functions and the properties of Markov chains, Larsén and Mann (7) derived theoretical expressions for the attenuation ratios of annual wind speed maxima identified from deficient data sets with varying intermittency - and averaging intervals to those identified from interval compliant data. The validity of the derived expressions was tested for five stations in Denmark and three in Egypt by synthesizing interval deficient data sets from sets of interval compliant data acquired at these stations. It was found that the theory performs adequately for the extratropical Danish stations, particularly in respect of intermittency deficiencies. Using similar procedures as Larsén and Mann (7), Beljaars (8) investigated the influence of intermittency intervals and filtering on the identification of wind gusts. Zięba (9) and Conradsen et al. (10) employed the concept of an effective number of observations in order to determine unbiased estimates of the standard errors of the means of parameters derived from correlated data. The effective number of observations can be evaluated provided the autocorrelation function of the data is known. In view of the emphasis on the influence of varying intervals on annual Weibull parameters rather than that of different levels of auto-correlation, the Weibull parameters presented herein were derived with no regard for the level of interdependence between individual data records. This is also the case in commercial state-of-the-art wind data analysis software such as $\mathrm{WAsP}^{3}$ and WindRose ${ }^{4}$, both of which disregard auto-correlation in the identification of these parameters.

Evidence of the potential value of deficient wind data is provided by Agüera-Pérez et al. (11) who shows that a regional wind climate derived via basic interpolation methods and shear calculations performed on the statistics of long term wind data recorded as daily averages at $2 \mathrm{~m} \mathrm{AGL}$ at a relatively dense network of agricultural AWS in the South of Spain compare favourably with two advanced mesoscale computer simulations in the characterization of wind roses for test sites located in the identified wind climate. Wind data that are proven to be of value in spite of their particular deficiencies can be used to enhance the spatial - and temporal representativeness of wind data produced by more recently installed modern meteorological DAS networks of newcomers. In Namibia, the latter include the National Wind Resource Assessment Project of Namibia (NWRAP) and the Southern African Science Service Centre for Climate Change and Adaptive Land Management (SASSCAL). A brief description of the NWRAP network is presented in section 2, while the SASSCAL network is described by Strohbach (12). Further details on SASSCAL are available on their website (13). The networks of NWRAP and SASSCAL came into operation as from 2012 and analyses have shown that the DRR rendered by these networks far exceed that of the AWS network of NMS in its present state.

Although deficiencies in respect of the dynamic characteristics - and mounting positions of anemometers employed in the production of data are important determinants of the ultimate value of deficient data, investigations into these are beyond the scope of the present article. If data are rendered insufficiently valuable as a result of interval deficiencies, the effects of other deficiencies are of no practical consequence. However, in cases where the value of interval deficient data proves to be sufficient, these aspects should undoubtedly be investigated. Future investigations into wind data deficiencies resulting from non-compliant anemometer characteristics could benefit from the contributions of inter alia Miller et al. (14), Pedersen et al. (15), Gill (16) and Baynton (17) that report on the characteristics of Dines -, sonic -, helicoidal propeller - and mechanical wind totalising anemometers respectively and how these compare with cup anemometers of which the characteristics are presented by

\footnotetext{
${ }^{3}$ Wind Atlas Analysis and Application Program developed by the Department of Wind Energy of the Danish Technical University, Denmark Wind Data Analysis Tool developed by Centre for Renewable Energy Sources, Greece
} 
Dahlberg et al. (18). Related work was conducted by Williams and Siepker (19) who produced an electronically instrumented replica of the pressure plate wind indicator shown in fig. 1 and employed concurrent one-minute means - and - standard deviations of the deflection angle of the plate and of wind speeds measured by a calibrated cup anemometer to validate the calibration graduations shown on the device. Employing data produced by the magnet and electronic counter pickup device that may be visible on the right hand side of the rotor of the mechanical anemometer shown in fig. 2, Vogt (20) evaluated daily means of wind speed calculated from counter readings and compared these with daily means derived from wind data produced by a calibrated electronic anemometer of equal elevation located 3 $\mathrm{m}$ away. In agreement with Baynton (17), Vogt found that the transfer function of a cup anemometer cannot be accurately realized by a fixed gear ratio between the rotor and a counter, because an unbiased transfer function of such an instrument also requires an offset. Future work on wind data deficiencies related to the mounting positions of anemometers could draw on the contributions of Orlando et al. (21) and Taylor and Salmon (22) who reported on the effects of tower shadow and sheltering by obstacles respectively and Cañadillas and Neumann (23) and Lubitz (24) who proposed equations for correcting wind data that are deficient in respect of mast interference.

Section 2 describes the procedures used in the creation of interval deficient data, as well as the details of the compliant DAS that produced the data from which the deficient data were synthesized. The procedures employed in the identification of Weibull parameters from the compliant - and interval deficient data are presented in section 3. The results of an analysis of the sensitivity of identified Weibull parameters to the length of intermittency - and averaging intervals are given in sections 4 and 5 respectively. Section 6 summarizes the findings of the study and identifies the wind measurement devices of which the interval deficient data that they produce could potentially be employed to identify Weibull parameters to the indicated accuracies.

\section{Methodology and compliant systems}

The maximum potential value of deficient data may be determined from data produced by systems that fully comply with the requirements of IEC $61400-12-1: 2005$ (E) (1). The procedure for an investigation into the effects of interval deficiency employs the data produced by the complaint systems to synthesize or simulate the interval deficient data produced by deficient systems. The very same systems that produced the interval compliant data therefore also produced the interval deficient data, which allows for an investigation of the effects of interval deficiency in isolation of any - and all of those of other possible causes of data deficiency, such as the dynamic response characteristics of the DAS or obstacle interference.

The compliant data employed in the simulations were produced by three DAS that form part of the wind measurement network of NWRAP and one DAS that is operated by the Wind Atlas Project of South Africa (WASA). NWRAP is a reduced cost national wind resource assessment project that during the first phase thereof employs a network of eleven high masts - three of which are dedicated wind masts and eight of which are telecommunication masts of opportunity - that are equipped with modern wind resource assessment DAS. NWRAP is a collaborative venture between the project partners GRTC, Mobile Telecommunications Limited (MTC), Namibia Power Corporation and Namibia University of Science and Technology, the latter which manages the project. The NWRAP DAS were commissioned between November 2011 and December 2013. A comprehensive description of NWRAP and the interim results covering the years 2013 and 2014 are presented by Siepker and Harms (25). The locations of the NWRAP masts are shown as the place markers in the Google Earth image presented in fig. 3. The locations of the dedicated wind masts at Walvis Bay, Gobabeb and Lüderitz are indicated with black spots inside the markers, the remaining markers indicating the masts of opportunity. 


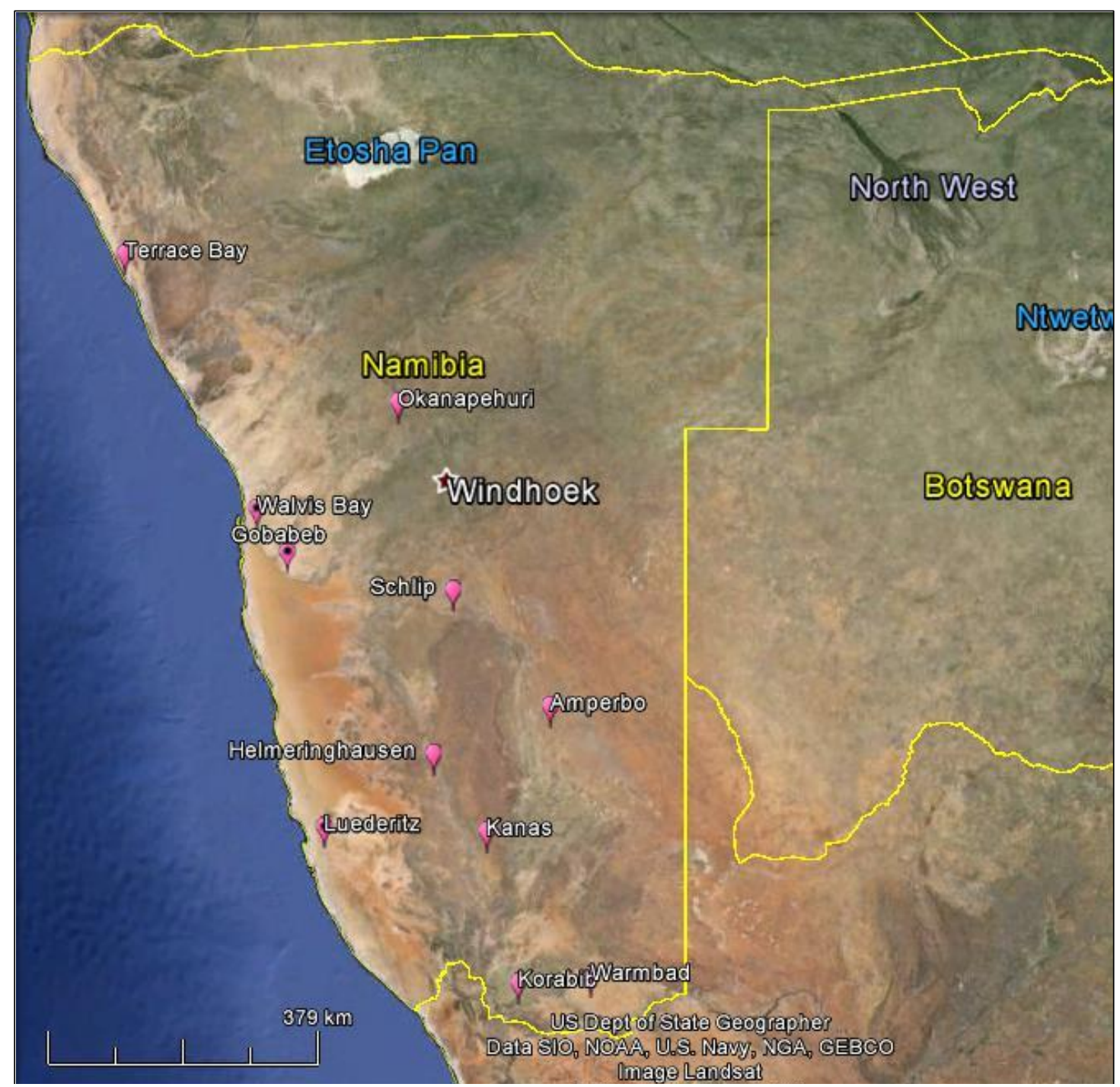

Fig. 3. Location of NWRAP masts

WASA is a wind resource assessment project for South Africa that during the first phase thereof employs a network of ten $60 \mathrm{~m}$ high dedicated wind masts that are equipped with modern wind resource assessment DAS. The details of the project are described by Otto (26). The location of the WASA station at Noupoort is indicated by the place marker shown in the Google Earth image that is presented in fig. 4. The locations of the four Southernmost NWRAP stations are also shown.

Annual sets of intermittency-deficient wind speed data were synthesized for the NWRAP stations at Terrace Bay, Gobabeb and Kanas and the WASA station at Noupoort by the deliberate omission of all data records from annual sets of compliant 10 minute (1 minute at Gobabeb) means other than the last data record in intermittency intervals of varying duration. An annual set of averaging interval deficient data was also synthesized for Gobabeb from an annual data set of compliant 1 minute means by the reduction of all data records in intervals of varying duration to a single data record, which is the average of all the 1 minute data records in the interval. This synthesis is therefore nothing other than the creation of the actual data records that would have been produced by the DAS at Gobabeb if the logger were physically set to a longer averaging interval. Intermittency - and averaging interval deficient data were synthesized for intervals of 10 - (only at Gobabeb), 20 - and 30 minutes - and 1 -, 2 -, 3 -, 4 - and 6 hours duration. 


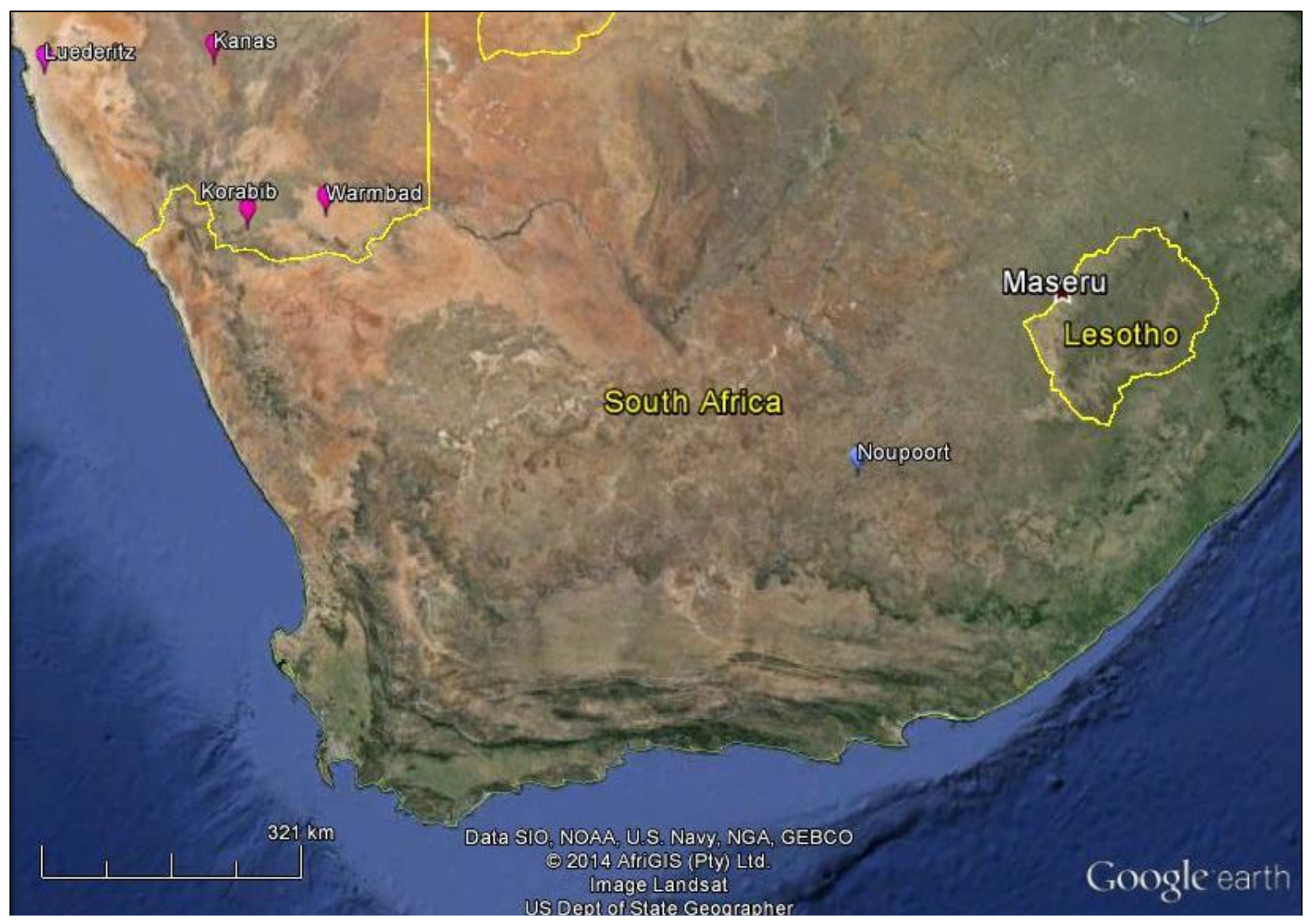

Fig. 4. Location of WASA station at Noupoort

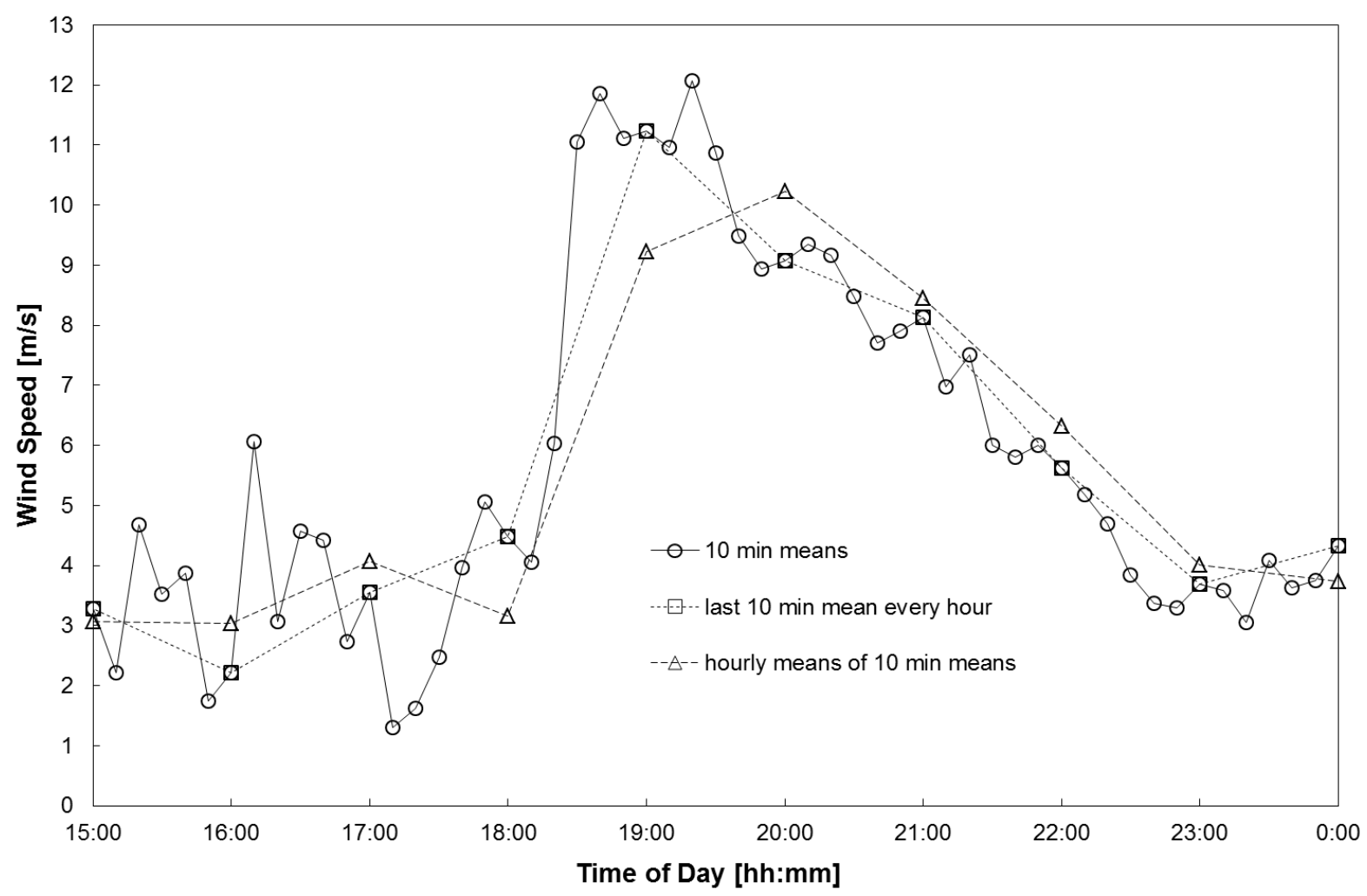

Fig. 5. Synthesis of deficient data of 1 hour intervals 
Fig. 5 shows an example of how intermittency - and averaging interval deficient data of 1 hour intervals were synthesized for a station with data records consisting of 10 minute means of wind speed. The circular markers represent the 10 minute means of the compliant data. The square markers represent the deficient hourly intermittent data and are the values of the last 10 minute mean of every hour. The triangular markers represent the deficient hourly averaging data and are the means of the six 10 minute means over every hour.

The Gobabeb data were produced by a DAS that is mounted on a slender $30 \mathrm{~m}$ tall mast of GRTC and is located approximately $1.5 \mathrm{~km}$ North-East of Gobabeb. This village, which is the seat of GRTC, is located in the central Namib desert approximately $90 \mathrm{~km}$ South East of the harbour town of Walvis Bay and approximately $55 \mathrm{~km}$ away from the closest point on the Atlantic Coast. GRTC was founded in 1962 and is an internationally recognized centre of excellence for the study of arid environments. A detailed description of GRTC and the research activities conducted there during the first 50 years of operation are given by Henschel and Lancaster (27). With comprehensive wind data sets produced by concurrently operated anemometers of varying technological sophistication over a period spanning more than five decades, GRTC offers interesting opportunities for investigations into the effects of the dynamic response characteristics of these anemometers on the quality of the data they produced, which in turn could open up further possibilities for analyses of long term wind regime changes. The anemometers employed by GRTC to date are a pressure plate wind indicator, a mechanical wind totalizer, several mechanical autographic wind recorders, several types of electronic cup anemometers, helicoidal propeller anemometers and sonic anemometers.

The GRTC mast and its present instrumentation are shown in fig. 6 . The triangular cross section guyed mast with a face width of $450 \mathrm{~mm}$ has round section structural members and is extensively instrumented for the purposes of wind resource assessment as well as micrometeorological research. The mast is located on a flat open sandy desert plain essentially devoid of vegetation and obstacles for several kilometres around the mast. The two calibrated NRG\#40C anemometers that are labelled in fig. 6 are the property of NWRAP and are used for wind resource assessment, whereas the other instrumentation is used by the University of Basel (UoB) and the Karlsruhe Institute of Technology (KIT) for micrometeorological research. This instrumentation includes the Campbell Scientific ASPTC aspirated dry bulb air temperature sensor and the Vaisala WAV15 wind vane that are also labelled in fig. 6 . The data produced by these two sensors are shared between NWRAP, UoB and KIT. The mast has as solidity of $30 \%$. The NWRAP anemometers are mounted on round section booms that separate the centre lines of the anemometers from the centre of the mast by a distance $R$ equal to 3.3 mast face widths $L$. The centre line wind speed deficit for these values of $R / L$ ratio and solidity as defined in IEC 61400-12-1:2005(E) is $1 \%$, which complies with the requirements of the standard. Vertical stubs mounted on the end of the anemometer booms separate the centre points of the NWRAP anemometers and the top of the booms by a distance $r$ equal to 12 boom diameters $d$. This $r / d$ ratio is slightly less than the ratio of 15 required for a $0.5 \%$ flow distortion in terms of the IEC standard, but it is in agreement with IEA Recommendation 11 (28) for the same amount of flow distortion. The angle between the centre lines of the booms and the direction of the prevalent wind is as close as possible to perpendicular as the mast face orientation allows. A Campbell Scientific CS3000 data logger integrates the output pulses of the anemometers over a sampling interval of 2 seconds and calculates the wind speed for every sampling interval via the anemometer calibration transfer function. This sampling interval is double that of the 1 second sampling interval specified by the IEC standard. From 30 values of wind speed calculated for every two-second sampling interval, the data logger calculates the mean -, standard deviation -, minimum - and maximum values of wind speed over every one minute interval - the averaging interval - and stores these values as the data record for the averaging interval of which a time stamp identifies the ends. This averaging interval is one tenth of that specified by the IEC standard. 


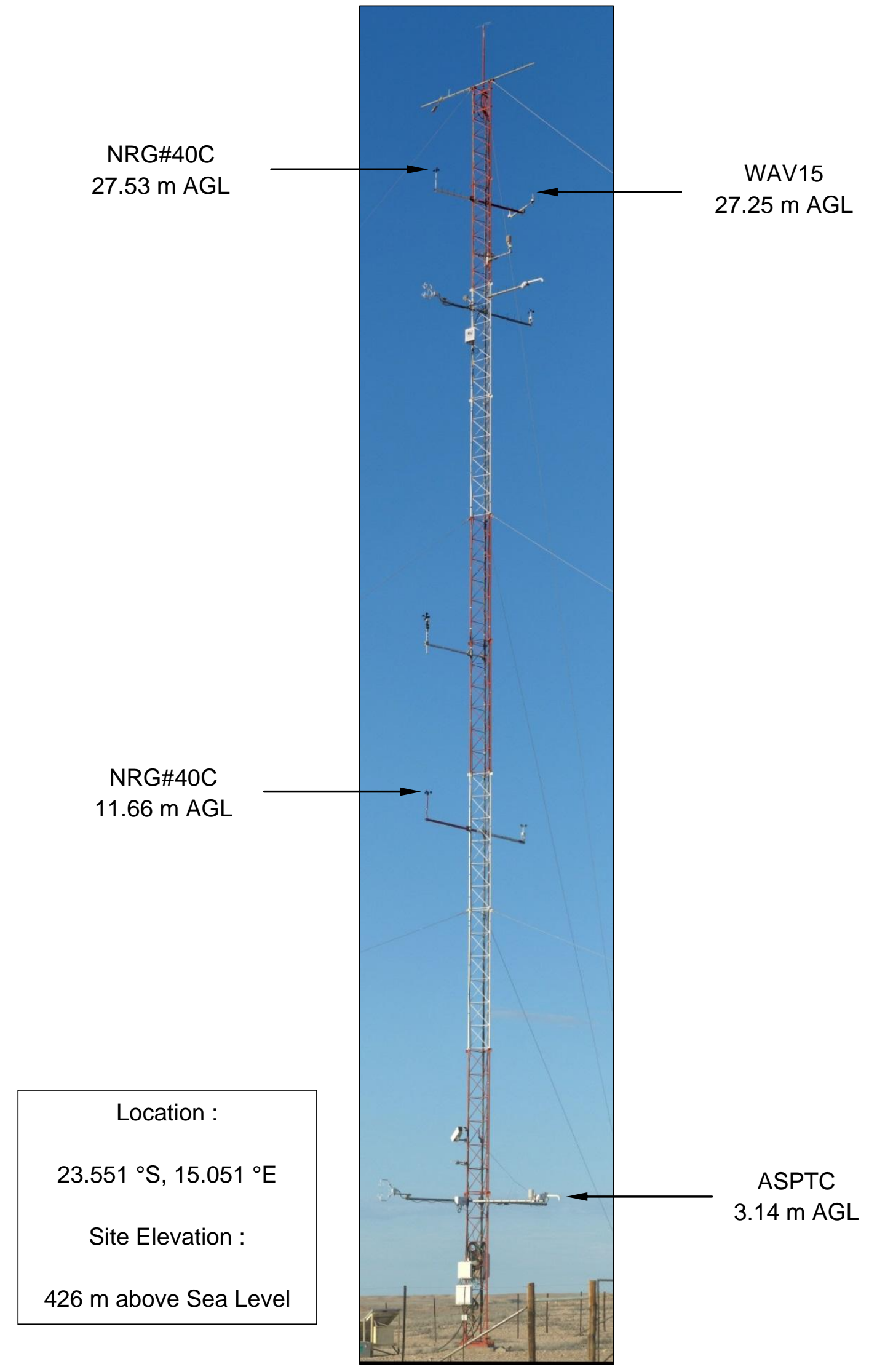

Fig. 6. GRTC $30 \mathrm{~m}$ mast and instrumentation ${ }^{5}$

${ }^{5}$ Photo courtesy Dr Roland Vogt (University of Basel) 
The Kanas data were produced by a DAS that is mounted on an $80 \mathrm{~m}$ tall telecommunications mast of MTC that is located in flat terrain at $26.775^{\circ} \mathrm{S}$ and $17.473^{\circ} \mathrm{E}$ which is approximately $450 \mathrm{~km}$ away from Gobabeb. The Terrace Bay data were produced by a DAS that is mounted on a $48 \mathrm{~m}$ tall telecommunications mast of MTC that is located on a small hill at $19.993^{\circ} \mathrm{S}$ and $13.040^{\circ} \mathrm{E}$, just outside the coastal village of Terrace Bay that is approximately $450 \mathrm{~km}$ and $880 \mathrm{~km}$ away from Gobabeb and Kanas respectively. Both DAS at Terrace Bay and Kanas consist of a Nomad 2 wind energy data logger, two calibrated SW C3 cup anemometers that are mounted at nominal elevations of $20 \mathrm{~m}$ and $50 \mathrm{~m} \mathrm{AGL}$, one SW PV-1 wind vane, one SWI thermistor for the measurement of ambient dry bulb air temperature and one Licor 200SZ pyranometer for the measurement of global horizontal solar radiation. Each Nomad 2 data logger integrates the output pulses of the anemometers over a sampling interval of 1 second and calculates the wind speed for every sampling interval via the anemometer calibration transfer function. This sampling interval is the same as that specified by the IEC standard. From 600 values of wind speed calculated for every one-second sampling interval, the data logger calculates the mean -, standard deviation -, minimum - and maximum values of wind speed over every ten minute interval - the averaging interval - and stores these values as the data record for the averaging interval of which a time stamp identifies the ends. This averaging interval is the same as that specified by the IEC standard.

The Kanas and Terrace Bay masts are guyed and have a triangular footprint and structural members with sharp edges. The solidity is estimated to be around $40 \%$ and the face widths $L$ are $1.32 \mathrm{~m}$ and $1.16 \mathrm{~m}$ respectively. All anemometers are mounted on round section booms that separate the centre lines of the anemometers from the centre of the mast by a distance $R$ equal to 2.45 and 2.72 mast face widths $L$ respectively. The centre line wind speed deficit for these values of R/L ratio and solidity is estimated to be in the order of 2.5 $\%$, which is $1.5 \%$ shy of the requirements of the standard. The $\mathrm{r} / \mathrm{d}$ ratios at Kanas and Terrace Bay are the same as at Gobabeb and the angle between the centre lines of the booms and the direction of the prevalent wind is also as close as possible to perpendicular as the mast face orientation allows. Fig. 7 shows the details of the wind vane boom mast interface employed at Kanas. All NWRAP booms are simple cantilevers that are clamped to the masts.

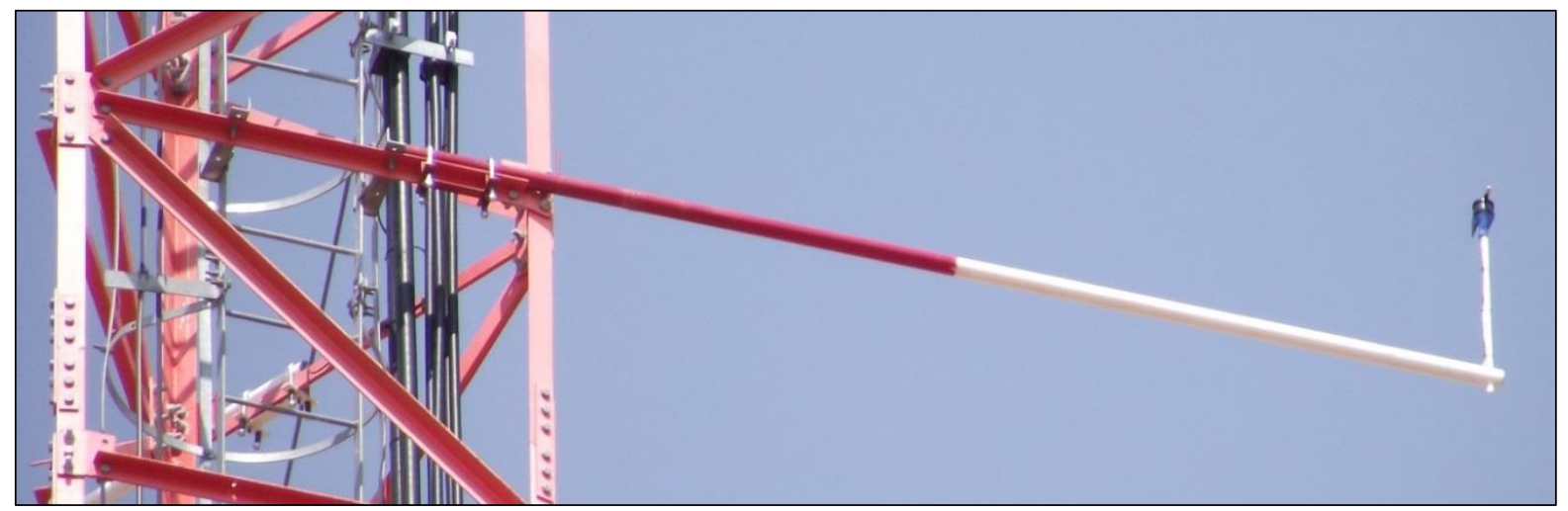

Fig. 7. Wind vane boom mast interface at Kanas

The Noupoort data were produced by a DAS that is mounted on a $60 \mathrm{~m}$ tall dedicated wind mast of WASA that is located at $25.028^{\circ} \mathrm{S}$ and $31.253^{\circ} \mathrm{E}$, which is approximately 890 $\mathrm{km}, 1300 \mathrm{~km}$ and $1730 \mathrm{~km}$ away from Kanas, Gobabeb and Terrace Bay respectively. The DAS at Noupoort consists of a Campbell Scientific CR 1000 data logger, five calibrated Wind Sensor P2546A cup anemometers that are mounted at nominal elevations of $10 \mathrm{~m}, 20 \mathrm{~m}, 40$ $\mathrm{m}, 60 \mathrm{~m}$ and $62 \mathrm{~m} \mathrm{AGL}$, two Vector Instruments W200P wind vanes, one Campbell Scientific HMP45C for the measurement of ambient dry bulb air temperature and relative humidity, 
one Vaisala PTB110 barometric pressure sensor and a pair of Risø P2642A temperature difference sensors. The CR 1000 data logger integrates the output pulses of the anemometers over a sampling interval of $0.5 \mathrm{~s}$ and calculates the wind speed for every sampling interval via the anemometer calibration transfer functions. This sampling interval is half of that specified by the IEC standard. From 1200 values of wind speed calculated for every half-second sampling interval, the data logger calculates the mean -, standard deviation -, minimum - and maximum values of wind speed over every ten minute interval the averaging interval - and stores these values as the data record for the averaging interval of which a time stamp identifies the ends. This averaging interval is the same as that specified by the IEC standard. The Noupoort mast is guyed and has a triangular footprint and structural members with round edges. The solidity is estimated to be around $30 \%$ and the face width $L$ is $300 \mathrm{~mm}$. The secondary anemometers are mounted on round section booms that separate the centre lines of the anemometers from the centre of the mast by a distance $R$ equal to 5.5 mast face widths $L$ respectively. The centre line wind speed deficit for these values of $\mathrm{R} / \mathrm{L}$ ratio and solidity is estimated to be in the order of $0.5 \%$, which is better than the $1 \%$ requirement of the standard. The primary anemometer is mounted vertically above the top of the mast as per the IEC standard. The r/d ratio of the secondary anemometers at Noupoort is presumed to be equal to - or better than 15 which is required for a $0.5 \%$ flow distortion in terms of the IEC standard.

\section{Identification of Weibull parameters}

The wind resource at any particular site, elevation and assessment interval may be characterized by wind parameters that are constants in a mathematical function called the probability density function (PDF). The PDF gives the probability of observing a particular wind speed $u$ at any given moment during the assessment period. One of the PDFs often used to characterize wind resources is the Weibull PDF. The wind parameters of this PDF are two Weibull parameters. The Weibull parameters are the scale factor $A[\mathrm{~m} / \mathrm{s}]$ and shape factor $k$ [1] as they appear in the PDF $f(u)$ [1] of the Weibull distribution that is given by :

$$
f(u)=\left(\frac{k}{A}\right)\left(\frac{u}{A}\right)^{k-1} \exp \left\{-\left(\frac{u}{A}\right)^{k}\right\}
$$

where $f(u)$ is the probability of observing wind speed $u$ at the site and elevation that has the Weibull factors $k$ and $A$. The expected value $E(u)$ is the mean $(\mu)$ of the wind speed $u$. CRES (29) shows that for the Weibull PDF $\mu$ is :

$$
\mu=\mathrm{E}(\mathrm{u})=\mathrm{A} \Gamma\left(1+\frac{1}{\mathrm{k}}\right)
$$

where $\Gamma$ is the Gamma function. From eq. (0) follows that :

$$
\mu^{2}=A^{2} \Gamma^{2}\left(1+\frac{1}{k}\right)
$$

The expected value $E\left(u^{2}\right)$ is the mean of the square of the wind speed $u$. For the Weibull PDF, Troen and Lundtang Petersen (30) show that: 
$E\left(u^{2}\right)=A^{2} \Gamma\left(1+\frac{2}{k}\right)$

The variance $\operatorname{Var}(u)$ of wind speed is the expected value or mean of the squared deviation of wind speed from the mean wind speed. From the properties of expected values and eqs. $(0)$ and $(0)$, it follows that $\operatorname{Var}(\mathrm{u})$ for the Weibull PDF is given by :

$$
\operatorname{Var}(u) \equiv \sigma_{u}^{2}=E\left\{(u-\mu)^{2}\right\}=E\left(u^{2}\right)-\mu^{2}=A^{2}\left\{\Gamma\left(1+\frac{2}{k}\right)-\Gamma^{2}\left(1+\frac{1}{k}\right)\right\}
$$

The expected value $E\left(u^{3}\right)$ is twice the air density normalized mean wind power density $\tilde{P}$ $\left[\mathrm{m}^{3} / \mathrm{s}^{3}\right]$ and for the Weibull PDF it can be shown that :

$$
2 \tilde{P}=E\left(u^{3}\right)=A^{3} \Gamma\left(1+\frac{3}{k}\right)
$$

If time series wind data are available, the Weibull parameters $k$ and $A$ may be identified from the sample mean $\bar{u}[\mathrm{~m} / \mathrm{s}]$ - and - variance $\mathrm{s}_{\mathrm{u}}^{2}\left[\mathrm{~m}^{2} / \mathrm{s}^{2}\right]$ of the time series data over the assessment period, as follows :

$$
\overline{\mathrm{u}}=\frac{1}{\mathrm{n}} \sum_{\mathrm{i}=1}^{\mathrm{i}=\mathrm{n}} \mathrm{u}_{\mathrm{i}}
$$

and

$$
\mathrm{s}_{\mathrm{u}}^{2}=\frac{1}{\mathrm{n}-1} \sum_{\mathrm{i}=1}^{\mathrm{i}=\mathrm{n}}\left(\mathrm{u}_{\mathrm{i}}-\overline{\mathrm{u}}\right)^{2}
$$

Although not used in the derivation of Weibull parameters in the present study, the observed air density normalized mean wind power density $\bar{P}\left[\mathrm{~m}^{3} / \mathrm{s}^{3}\right]$ is :

$$
\bar{P}=\frac{1}{n} \sum_{i=1}^{i=n} \frac{1}{2} u_{i}^{3}=\frac{1}{2 n} \sum_{i=1}^{i=n} u_{i}^{3}
$$

The values of $\bar{u}$ and $s_{u}^{2}$ recorded over an assessment period of a whole number of full years are used as estimators of $\mu$ and $\sigma_{u}^{2}$ so that from eqs. (0), (0), (0) and (0) :

$$
\overline{\mathrm{u}}^{2} \square \mu^{2}=\mathrm{A}^{2} \Gamma^{2}\left(1+\frac{1}{\mathrm{k}}\right) \Rightarrow \frac{\overline{\mathrm{u}}}{\mathrm{A}} \square \Gamma\left(1+\frac{1}{\mathrm{k}}\right) \Rightarrow \frac{\mathrm{A}}{\overline{\mathrm{u}}} \square\left\{\Gamma\left(1+\frac{1}{\mathrm{k}}\right)\right\}^{-1}
$$

and

$$
\mathrm{s}_{\mathrm{u}}^{2} \square \sigma_{\mathrm{u}}^{2}=\mathrm{A}^{2}\left\{\Gamma\left(1+\frac{2}{\mathrm{k}}\right)-\Gamma^{2}\left(1+\frac{1}{\mathrm{k}}\right)\right\}
$$


From $(0)$ and $(0)$ it follows that :

$\left(\frac{s_{u}}{\bar{u}}\right)^{2} \square\left(\frac{\sigma_{u}}{\mu}\right)^{2}=\frac{\Gamma\left(1+\frac{2}{k}\right)}{\Gamma^{2}\left(1+\frac{1}{k}\right)}-1=\frac{\Gamma(1+2 y)}{\Gamma^{2}(1+y)}-1 \Rightarrow g(y)=\frac{\Gamma(1+2 y)}{\Gamma^{2}(1+y)}-\left(\frac{s_{u}}{\bar{u}}\right)^{2}-1=0$

In the present study, the iterative Generalized Reduced Gradient Nonlinear option of the SOLVER function of MS Excel was employed to solve eq. (0) for the value of $y$ and thus $k$ that satisfies the equality. With $\mathrm{k}$ known, $\mathrm{A}$ is calculated from eq. (0). With both $\mathrm{k}$ and $\mathrm{A}$ known, $\tilde{P}$ is calculated from eq. (0). The described method that uses the sample mean $\bar{u}$ and the sample variance $s_{u}^{2}$ to identify Weibull parameters is known in the literature as the moment method as opposed to the so-called power density method that employs $\bar{u}$ and $\bar{P}$.

Several authors including Akdağ and Dinler (31) and Rocha et al (32) compare these methods with other methods in terms of a number of goodness of fit tests and report that not one single method is optimum in all cases. This finding perhaps explains why different commercial wind data analysis computer programs employ different identification methods, for example WindRose that employs the moment method and WAsP that utilises the power density method. However, as the emphasis in the present study is on the influence of the length of intervals and not the performance of identification methods, only the moment method is employed herein.

\section{Sensitivity of Weibull parameters to intermittency intervals}

\section{Gobabeb}

The moment method described in section 3 was used to identify the wind parameters from the one minute records of mean wind speed produced by both NRG\#40C anemometers on the $30 \mathrm{~m}$ mast at Gobabeb during 2013. The net data recovery rate (NDRR) was 97.85 $\%$. The values of these parameters at two elevations were then used as reference to evaluate the sensitivity of the wind parameters to varying percentages of deliberately discarded contiguous data records from the original complete set of one minute data. The percentage of discarded data records varies between $90 \%$ in the case where only the last one minute data record over a ten minute interval is retained and $99.72 \%$ in the case of discarding all data except for the last one minute data record over a six hour interval. These intervals are called the intermittency intervals. In all cases, the NDRR was $97.74 \%$ or better. The first intermittency interval of any size commences at $00 \mathrm{h00}$ every day and ends at the end of the interval. The next interval starts where the previous interval ends and the last interval of any size ends at $24 \mathrm{~h} 00$ every day. Six-hour intervals therefore for example end at $06 \mathrm{~h} 00,12 \mathrm{~h} 00,18 \mathrm{~h} 00$ and $24 \mathrm{~h} 00$ and four-hour intervals at $04 \mathrm{~h} 00,08 \mathrm{~h} 00,12 \mathrm{~h} 00,16 \mathrm{~h} 00$, $20 \mathrm{~h} 00$ and $24 \mathrm{~h} 00$. Each intermittency interval is represented by only the data recorded in the last minute before the end of the interval.

Table 1 presents the results of the intermittency interval sensitivity analysis for the data of the NRG\#40C anemometer at $27.53 \mathrm{~m} \mathrm{AGL}$ at Gobabeb. The leftmost two columns of table 1 show the length of the intermittency interval for which the indicated parameters were derived and the associated percentage of data omitted from the compliant one minute data file. The percentage difference between the value of a parameter $x$ for a particular intermittency interval and its value $x_{1}$ for the original one minute interval is the error $\Delta x$ and is calculated as : 
$\Delta x[\%]=\frac{100\left(x-x_{1}\right)}{x_{1}}$

\section{Table 1}

Intermittency interval sensitivity of wind parameters at 27.53 m AGL at Gobabeb

\begin{tabular}{cccccccccc}
\hline $\begin{array}{c}\text { Interval } \\
{[\mathrm{min}]}\end{array}$ & $\begin{array}{c}\text { Omit } \\
{[\%]}\end{array}$ & $\begin{array}{c}\overline{\mathrm{u}} \\
{[\mathrm{m} / \mathrm{s}]}\end{array}$ & $\begin{array}{c}\mathrm{S}_{\mathrm{u}} \\
{[\mathrm{m} / \mathrm{s}]}\end{array}$ & $\begin{array}{c}\mathrm{k} \\
{[1]}\end{array}$ & $\begin{array}{c}\Delta \mathrm{k} \\
{[\%]}\end{array}$ & $\begin{array}{c}\mathrm{A} \\
{[\mathrm{m} / \mathrm{s}]}\end{array}$ & $\begin{array}{c}\Delta \mathrm{A} \\
{[\%]}\end{array}$ & $\begin{array}{c}\tilde{\mathrm{P}} \\
{\left[\mathrm{m}^{3} / \mathrm{s}^{3}\right]}\end{array}$ & $\begin{array}{c}\Delta \tilde{\mathrm{P}} \\
{[\%]}\end{array}$ \\
\hline & & & & & & & & & \\
1 & 0.000 & 4.378 & 2.561 & 1.766 & - & 4.919 & - & 91.805 & - \\
10 & 90.000 & 4.378 & 2.562 & 1.765 & -0.061 & 4.918 & -0.008 & 91.858 & 0.058 \\
20 & 95.000 & 4.376 & 2.561 & 1.765 & -0.078 & 4.916 & -0.064 & 91.727 & -0.086 \\
30 & 96.667 & 4.374 & 2.569 & 1.758 & -0.464 & 4.912 & -0.129 & 92.030 & 0.245 \\
60 & 98.333 & 4.366 & 2.568 & 1.755 & -0.627 & 4.903 & -0.321 & 91.705 & -0.109 \\
120 & 99.166 & 4.391 & 2.561 & 1.772 & 0.306 & 4.933 & 0.299 & 92.249 & 0.484 \\
180 & 99.444 & 4.344 & 2.577 & 1.739 & -1.561 & 4.876 & -0.868 & 91.388 & -0.454 \\
240 & 99.583 & 4.403 & 2.594 & 1.752 & -0.828 & 4.943 & 0.504 & 94.262 & 2.677 \\
360 & 99.722 & 4.271 & 2.414 & 1.834 & 3.815 & 4.806 & -2.286 & 81.572 & -11.147 \\
\hline
\end{tabular}

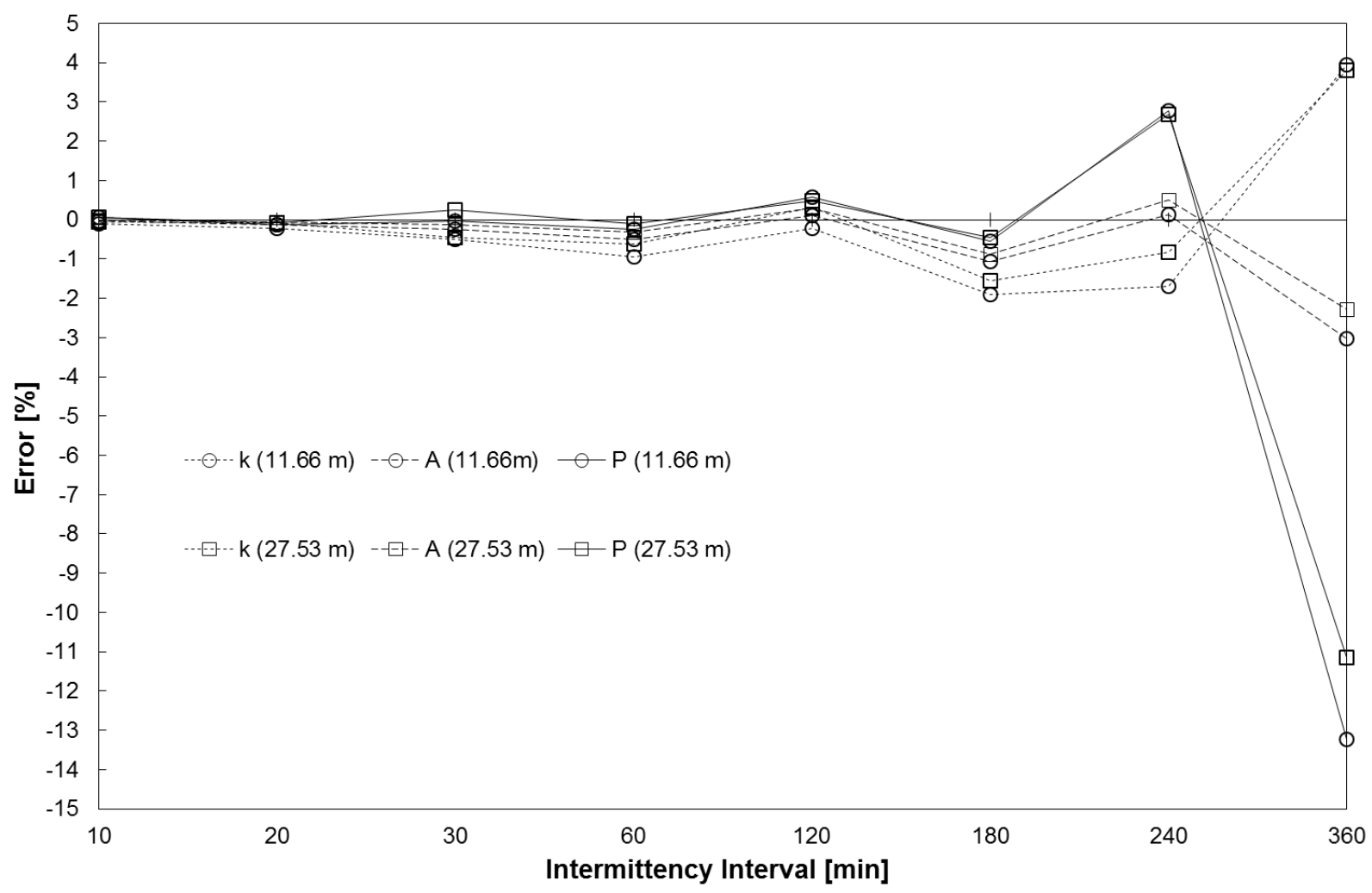

Fig. 8. Intermittency interval errors of wind parameters at Gobabeb

A similar analysis was made with the data produced by the NRG\#40C anemometer at $11.66 \mathrm{~m}$ AGL at Gobabeb. Fig. 8 is a chart of the intermittency interval errors in $\mathrm{k}, \mathrm{A}$ and $\tilde{P}$ at both elevations at Gobabeb for 2013. From table 1 and fig. 8 it may be observed that all the indicated wind parameters identify to within $1 \%$ of the one minute reference values for intermittency intervals of up to two hours, which represents $0.83 \%$ of the original amount of 
compliant data. The air density normalized mean wind power density identified from data recorded during the last minute of every six hour interval is within $14 \%$ of its reference value, with the other wind parameters being within $4 \%$ of their reference values. The errors are seen to generally increase with increasing length of intermittency interval. The error in A is in general smaller than the other errors.

\section{Terrace Bay, Kanas and Noupoort}

Intermittency interval sensitivity analyses similar to those for Gobabeb were also conducted on the data produced by both anemometers at Terrace Bay and Kanas during 2013 and the topmost anemometer at Noupoort in 2015. For these stations, the percentage of omitted data records varies between $50 \%$ in the case where only the last ten minute data record over a twenty minute interval is retained and $97.22 \%$ in the case of discarding all data except for the last ten minute data record over a six hour interval. In all cases, the NDRR was $100 \%$. Table 2 presents the results of the intermittency interval sensitivity analysis for the data of the anemometer at $21.20 \mathrm{~m} \mathrm{AGL}$ at Terrace Bay.

Table 2

Intermittency Interval Sensitivity of Wind Parameters at $21.20 \mathrm{~m}$ at Terrace Bay

\begin{tabular}{cccccccccc}
\hline $\begin{array}{c}\text { Interval } \\
{[\mathrm{min}]}\end{array}$ & $\begin{array}{c}\text { Omit } \\
{[\%]}\end{array}$ & $\begin{array}{c}\overline{\mathrm{u}} \\
{[\mathrm{m} / \mathrm{s}]}\end{array}$ & $\begin{array}{c}\mathrm{S}_{\mathrm{u}} \\
{[\mathrm{m} / \mathrm{s}]}\end{array}$ & $\begin{array}{c}\mathrm{k} \\
{[1]}\end{array}$ & $\begin{array}{c}\Delta \mathrm{k} \\
{[\%]}\end{array}$ & $\begin{array}{c}\mathrm{A} \\
{[\mathrm{m} / \mathrm{s}]}\end{array}$ & $\begin{array}{c}\Delta \mathrm{A} \\
{[\%]}\end{array}$ & $\begin{array}{c}\beta 6 \\
{\left[\mathrm{~m}^{3} / \mathrm{s}^{3}\right]}\end{array}$ & $\begin{array}{c}\Delta \tilde{\mathrm{P}} \\
{[\%]}\end{array}$ \\
\hline & & & & & & & & & \\
10 & 0.000 & 5.903 & 2.872 & 2.166 & - & 6.666 & - & 182.148 & - \\
20 & 50.000 & 5.902 & 2.871 & 2.166 & 0.007 & 6.665 & -0.016 & 182.049 & -0.054 \\
30 & 66.667 & 5.901 & 2.877 & 2.161 & -0.234 & 6.663 & -0.036 & 182.332 & 0.101 \\
60 & 83.333 & 5.897 & 2.876 & 2.160 & -0.272 & 6.659 & -0.099 & 182.051 & -0.054 \\
120 & 91.666 & 5.886 & 2.881 & 2.152 & -0.669 & 6.646 & -0.296 & 181.628 & -0.286 \\
180 & 94.444 & 5.871 & 2.883 & 2.144 & -1.029 & 6.630 & -0.542 & 180.882 & -0.695 \\
240 & 95.833 & 5.914 & 2.915 & 2.135 & -1.438 & 6.678 & 0.182 & 185.565 & 1.876 \\
360 & 97.222 & 5.726 & 2.828 & 2.131 & -1.650 & 6.465 & -3.009 & 168.729 & -7.367 \\
\hline
\end{tabular}

Fig. 9 is a chart of the intermittency interval errors in $k, A$ and $\tilde{P}$ at both elevations at Terrace Bay for 2013. The intermittency interval errors of the wind parameters derived for the anemometers at Kanas and Noupoort (62 m AGL) are shown in figs. 10 and 11 respectively. From table 2 and figs. 9 to 11 it may be observed that all the indicated wind parameters identify to within $0.5 \%$ of the ten minute reference values for intermittency intervals of up to one hour. Like in the case of Gobabeb, the errors generally increase with increasing intermittency interval and the error in $A$ is generally smaller than the other errors.

At Noupoort, all the wind parameters identify to within $2 \%$ of the ten minute reference values for intermittency intervals of up to six hours, which represents $2.78 \%$ of the original amount of compliant data. This insensitivity is emphasized in fig. 12 which shows the measured binned wind speed distributions at Noupoort (62 m AGL) as determined from the deficient data sets for the indicated intermittency intervals, as well as the binned Weibull distributions for the Weibull parameters derived from the 52560 data records in the set of compliant data and the 1460 data records in the deficient set of six-hour intermittency data. Although the binned Weibull distributions are not continuous, they are indicated by continuous lines for clarity. It is seen that the two binned Weibull distributions that are derived from data sets of vastly different size, are virtually indistinguishable. 


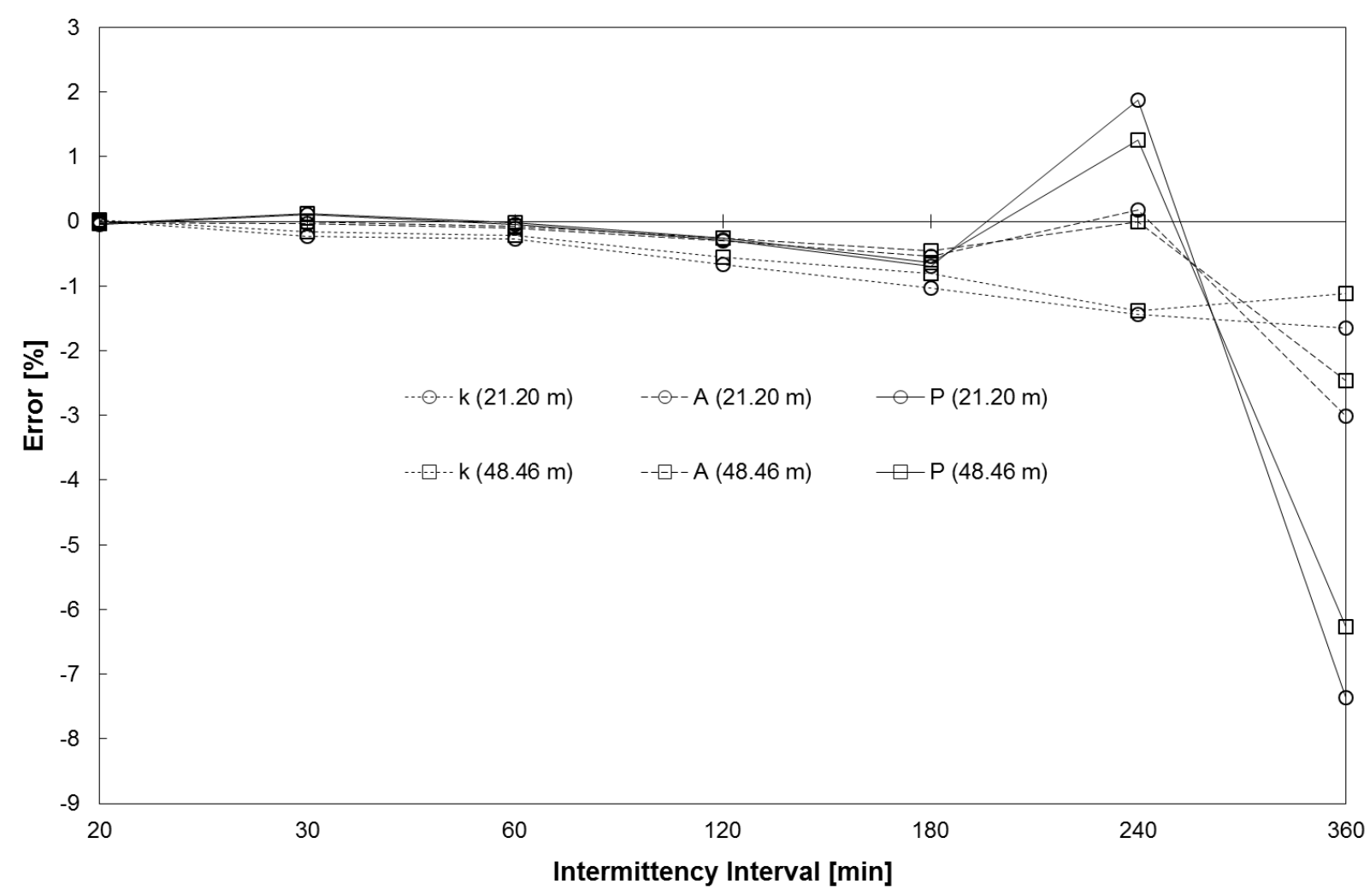

Fig. 9. Intermittency interval errors of wind parameters at Terrace Bay

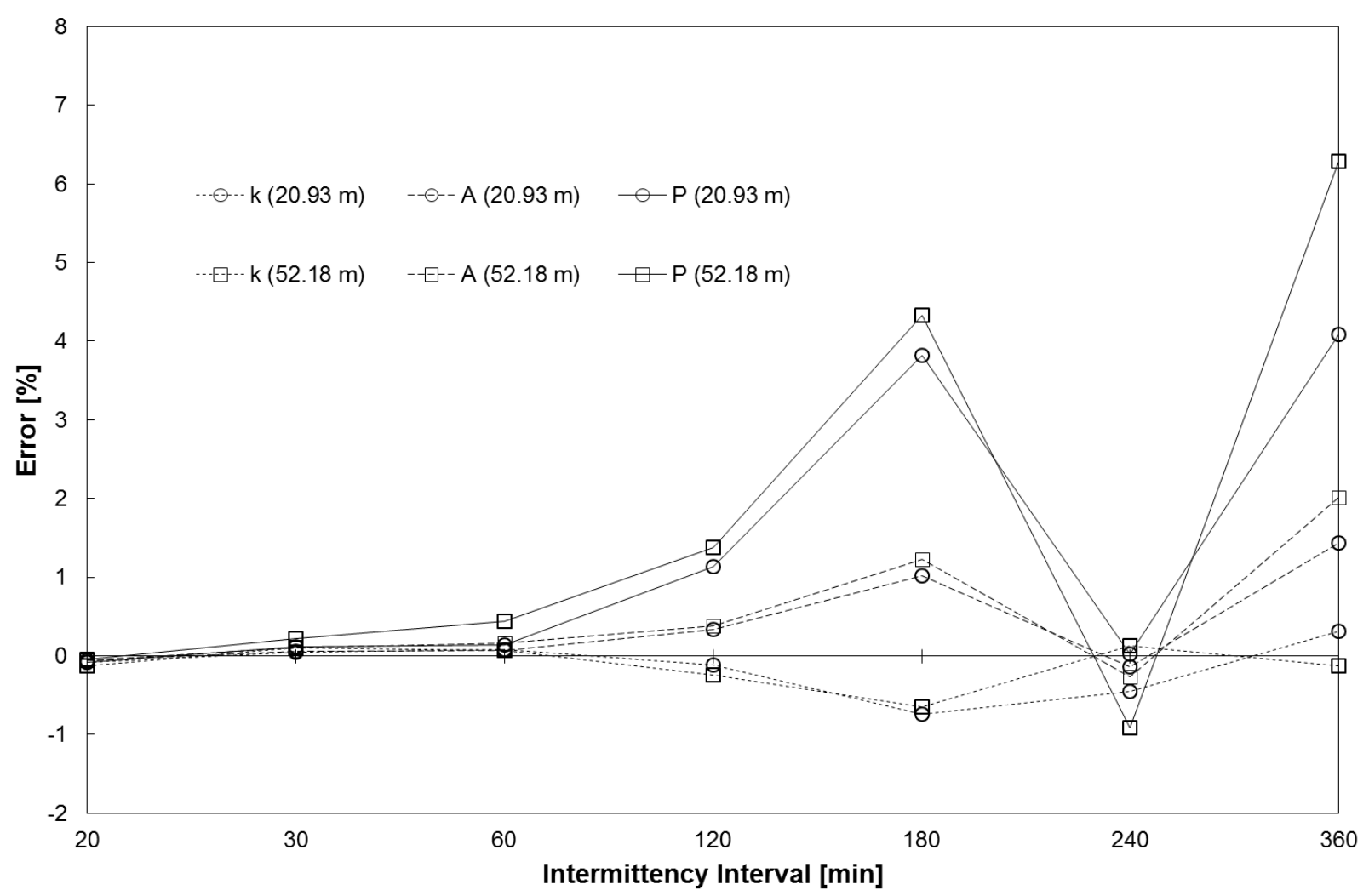

Fig. 10. Intermittency interval errors of wind parameters at Kanas 


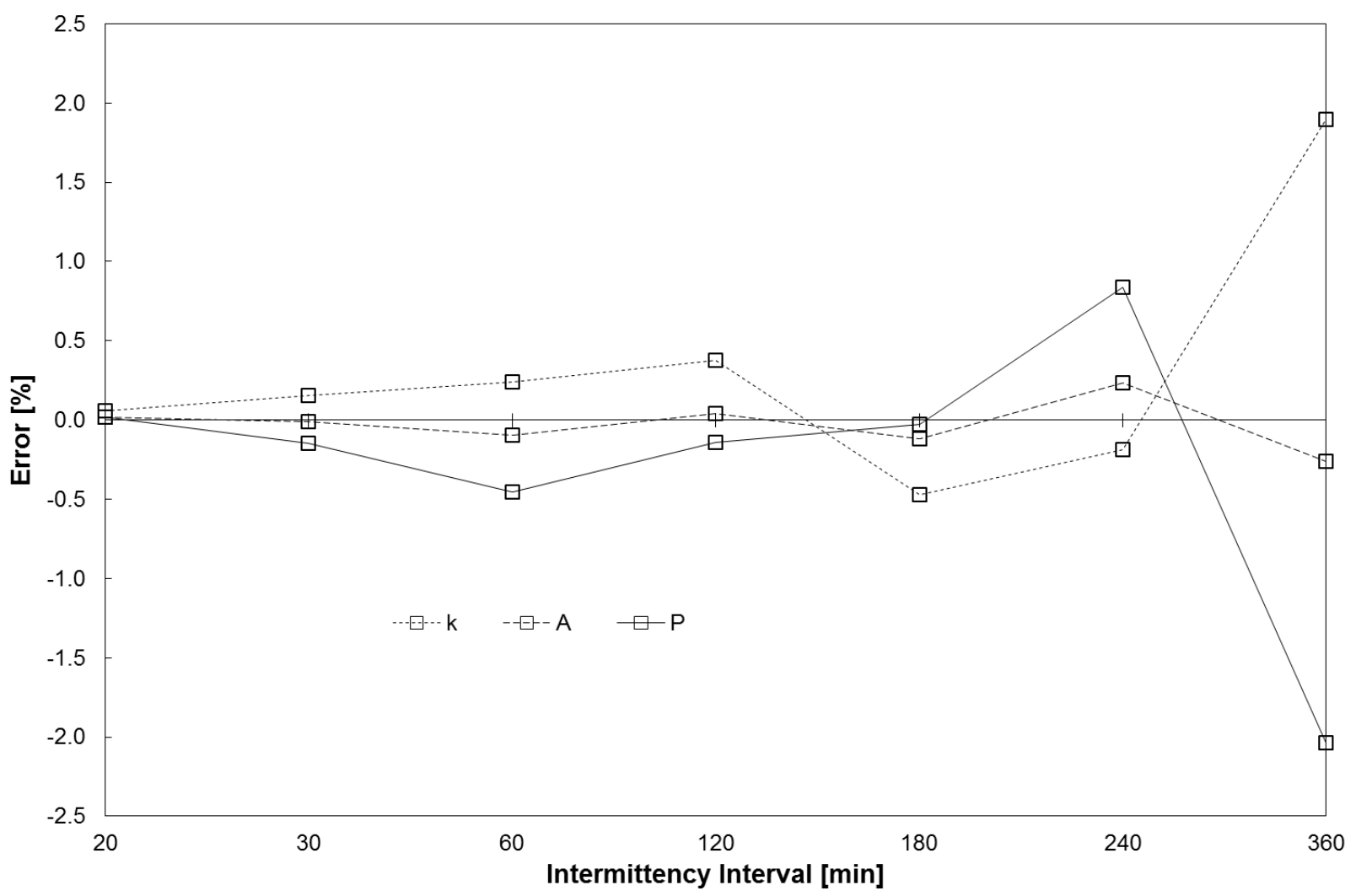

Fig. 11. Intermittency interval errors of wind parameters at Noupoort

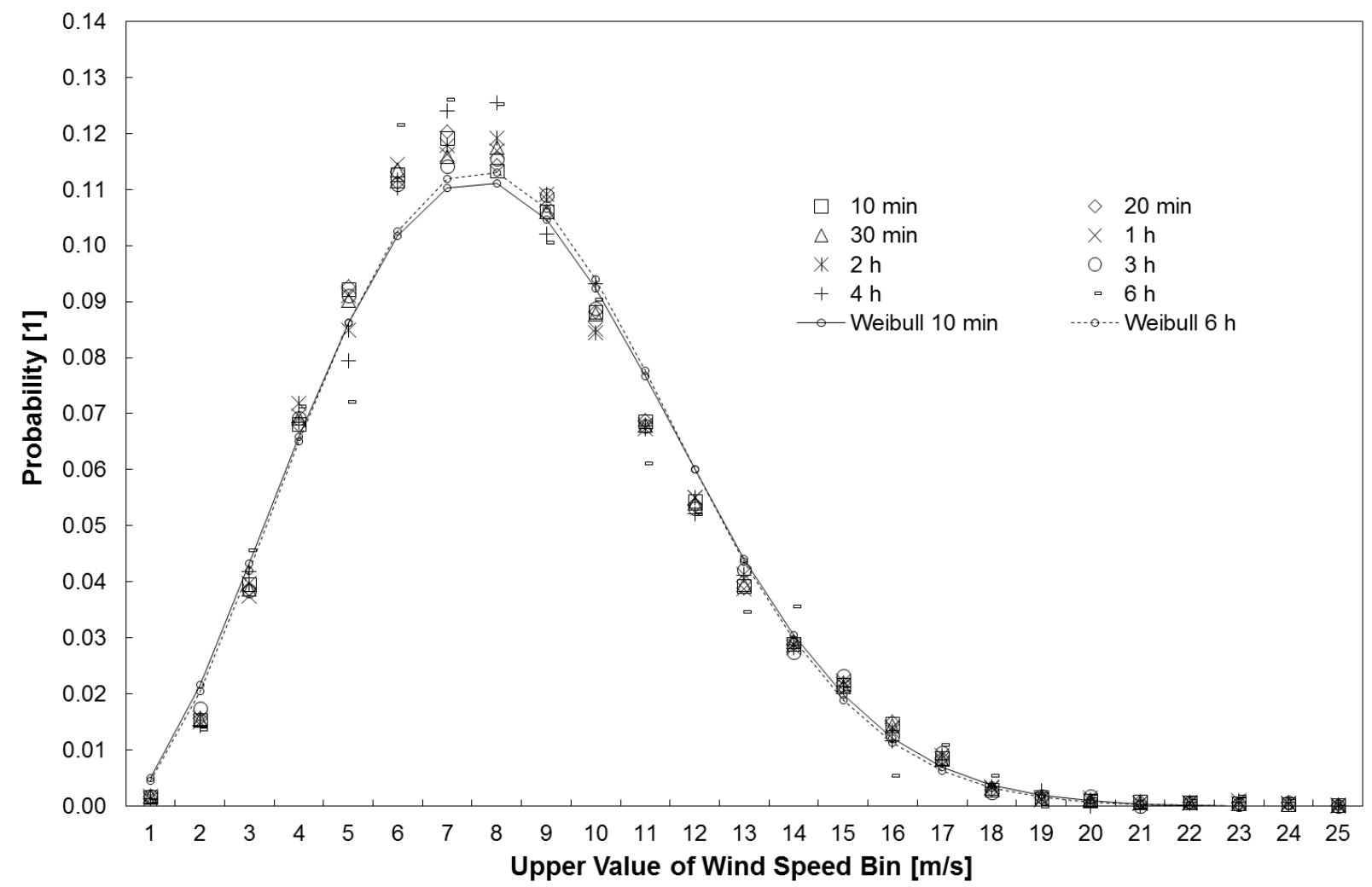

Fig. 12. Binned wind speed distributions at Noupoort 
The absolute errors of the wind parameters of which the percentage errors are given in tables 1 and 2 and figs. 8 to 11 may be obtained from table 3 that presents the wind statistics derived from the compliant data sets which consist of one-minute means at Gobabeb and ten-minute means at the other stations. The parameters presented in the third, fourth and fifth columns of table 3 are the observed statistics as calculated from eqs. (0), (0) and (0). The indicated Weibull parameters were derived from the observed statistics using the moment method. The parameters presented in the last three columns were calculated from the Weibull parameters using eqs.(0), (0) and (0) and therefore are the modelled equivalents of the respective observed parameters. It may be evident that the modelled parameters are in excellent agreement with the observed parameters, the largest deviations being in the order of $1 \%$ for the air density normalized mean wind power density and no discernible difference between the other two parameters. This is an indication that the Weibull PDF is a good model for the wind regimes at all the analysed stations.

Table 3

Wind statistics derived from compliant data sets

\begin{tabular}{cccccccccc}
\hline Station & $\begin{array}{c}\text { Elevation } \\
{[\mathrm{m} \mathrm{AGL}]}\end{array}$ & $\begin{array}{c}\overline{\mathrm{u}} \\
{[\mathrm{m} / \mathrm{s}]}\end{array}$ & $\begin{array}{c}\mathrm{S}_{\mathrm{u}} \\
{[\mathrm{m} / \mathrm{s}]}\end{array}$ & $\begin{array}{c}\overline{\mathrm{P}} \\
{\left[\mathrm{m}^{3} / \mathrm{s}^{3}\right]}\end{array}$ & $\begin{array}{c}\mathrm{k} \\
{[1]}\end{array}$ & $\begin{array}{c}\mathrm{A} \\
{[\mathrm{m} / \mathrm{s}]}\end{array}$ & $\begin{array}{c}\mu \\
{[\mathrm{m} / \mathrm{s}]}\end{array}$ & $\begin{array}{c}\sigma_{\mathrm{u}} \\
{[\mathrm{m} / \mathrm{s}]}\end{array}$ & $\begin{array}{c}\beta b \\
{\left[\mathrm{~m}^{3} / \mathrm{s}^{3}\right]}\end{array}$ \\
\hline \multirow{3}{*}{ Terrace Bay } & 21.20 & 5.903 & 2.872 & 180.6 & 2.166 & 6.666 & 5.903 & 2.872 & 182.1 \\
& 48.46 & 6.136 & 2.993 & 202.7 & 2.160 & 6.929 & 6.136 & 2.993 & 205.1 \\
Gobabeb & 11.66 & 4.143 & 2.414 & 76.7 & 1.773 & 4.656 & 4.143 & 2.414 & 77.4 \\
& 27.53 & 4.378 & 2.561 & 92.0 & 1.766 & 4.919 & 4.378 & 2.561 & 91.8 \\
Kanas & 20.93 & 4.939 & 2.454 & 109.7 & 2.116 & 5.577 & 4.939 & 2.454 & 109.0 \\
& 52.18 & 5.775 & 2.781 & 169.0 & 2.191 & 6.521 & 5.775 & 2.781 & 168.8 \\
Noupoort & 62.00 & 7.825 & 3.433 & 390.8 & 2.431 & 8.825 & 7.825 & 3.433 & 385.8 \\
\hline
\end{tabular}

\section{$\underline{\text { Offset Error }}$}

It may be observed from fig. 8 to 11 that the errors in the wind parameters in general increase with increasing intermittency interval and that in all cases the maximum errors are recorded at intermittency intervals of six hours. In order to assess whether the larger errors are perhaps ascribable to the poor timing of longer interval intermittent observations, further investigation into the relatively larger errors associated with longer intermittency intervals was conducted by the introduction of time offsets that were varied between one and six hours. A time offset is a forward time shift of the end of an intermittency interval away from the regular end of that same interval as previously specified in section 4 . A time offset of three hours therefore for example implies that the time interval starts at the regular end of an interval plus three hours. In the case of six-hour intervals with an offset of three hours, the first interval of every day therefore ends at $03 \mathrm{~h} 00$ and the six-hour intervals thereafter at 09h00, $15 \mathrm{~h} 00$ and $21 \mathrm{~h} 00$.

Table 4 and fig. 13 present the results of the offset sensitivity analysis for the deficient six-hour intermittency data of the NRG\#40C anemometer at $11.66 \mathrm{~m} \mathrm{AGL}$ at Gobabeb. The errors in table 4 and fig. 13 are calculated as per eq. Error! Reference source not found., the reference still being the value of the relevant parameter for the one-minute compliant interval. All three the offset error curves in fig. 13 demonstrate symmetry about the 3 hour offset point and the errors at 0 hour - and 6 hour offsets are very close to equal for each parameter. The latter observation is logical, as bar one data point at each of the beginning and end of the year, the two offset errors are calculated from the same selection of data points. 
Table 4

Offset sensitivity of wind parameters at $11.66 \mathrm{~m} \mathrm{AGL}$ at Gobabeb

\begin{tabular}{ccccccccc}
\hline $\begin{array}{c}\text { Offset } \\
\text { [hours] }]\end{array}$ & $\begin{array}{c}\overline{\mathrm{u}} \\
{[\mathrm{m} / \mathrm{s}]}\end{array}$ & $\begin{array}{c}\mathrm{S}_{\mathrm{u}} \\
{[\mathrm{m} / \mathrm{s}]}\end{array}$ & $\begin{array}{c}\mathrm{k} \\
{[1]}\end{array}$ & $\begin{array}{c}\Delta \mathrm{k} \\
{[\%]}\end{array}$ & $\begin{array}{c}\mathrm{A} \\
{[\mathrm{m} / \mathrm{s}]}\end{array}$ & $\begin{array}{c}\Delta \mathrm{A} \\
{[\%]}\end{array}$ & $\begin{array}{c}\beta_{0} \\
{\left[\mathrm{~m}^{3} / \mathrm{s}^{3}\right]}\end{array}$ & $\begin{array}{c}\Delta \tilde{\mathrm{P}} \\
{[\%]}\end{array}$ \\
\hline & & & & & & & & \\
0 & 4.011 & 2.872 & 1.843 & 3.942 & 4.515 & -3.018 & 67.182 & -13.228 \\
1 & 4.036 & 2.871 & 1.783 & 0.535 & 4.536 & -2.569 & 71.101 & -8.167 \\
1.5 & 4.103 & 2.877 & 1.729 & -2.480 & 4.604 & -1.104 & 77.518 & 0.122 \\
2 & 4.188 & 2.876 & 1.714 & -3.320 & 4.679 & 0.882 & 83.301 & 7.591 \\
3 & 4.194 & 2.881 & 1.660 & -6.363 & 4.692 & 0.791 & 87.097 & 12.495 \\
4 & 4.238 & 2.883 & 1.768 & -0.274 & 4.762 & 2.279 & 83.145 & 7.390 \\
5 & 4.036 & 2.915 & 1.805 & 1.800 & 4.569 & -1.848 & 71.507 & -7.642 \\
6 & 4.009 & 2.828 & 1.843 & 3.923 & 4.512 & -3.075 & 67.079 & -13.361 \\
\hline
\end{tabular}

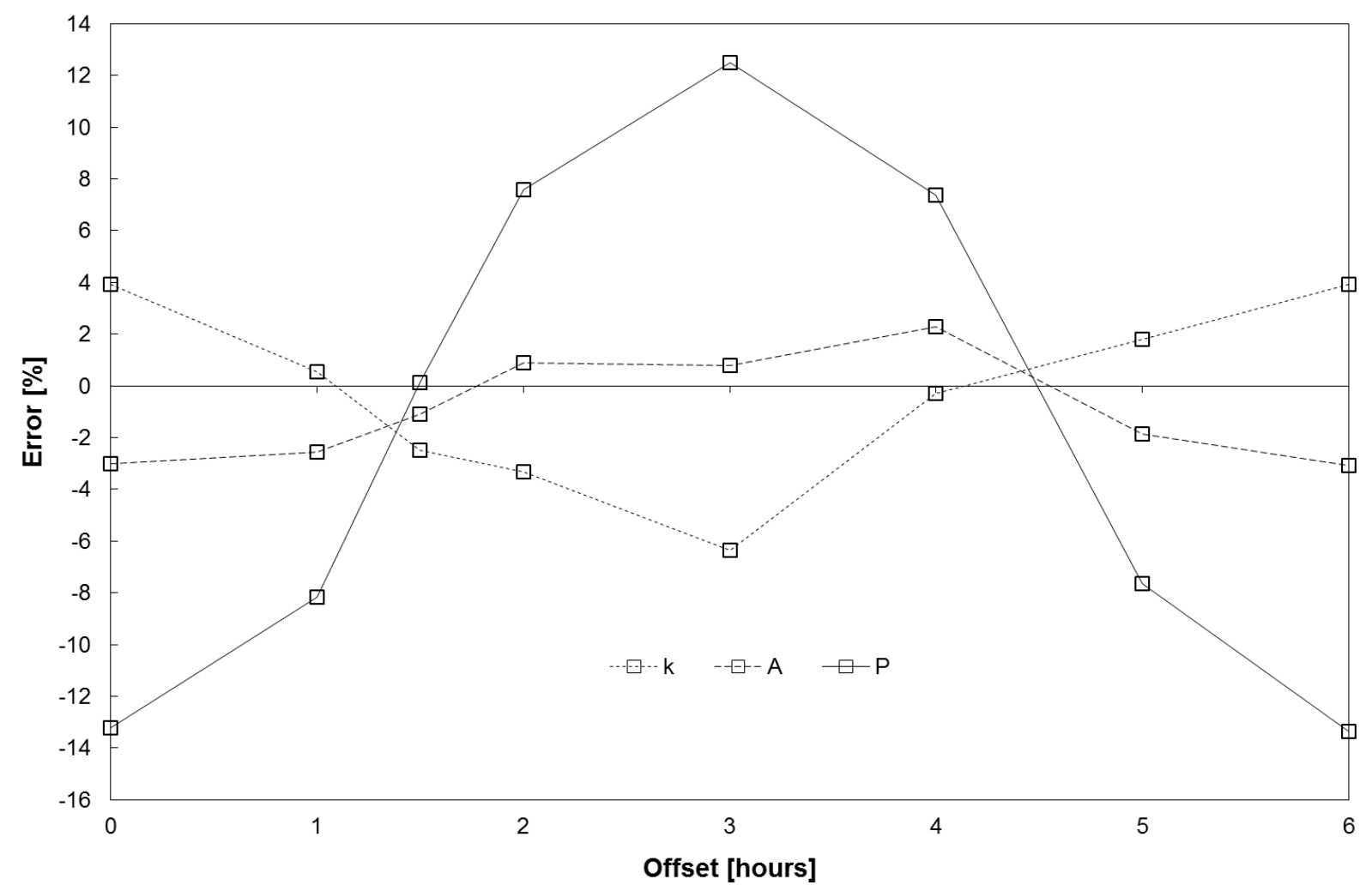

Fig. 13. Offset errors of wind parameters for 6 hour intermittency at Gobabeb

A zero offset error in $\beta^{\circ}$ (and small errors in $k$ and A) occurs at an offset of approximately 1.5 hours and its symmetry conjugate of 4.5 hours offset. The 1.5 hour offset first occurs one hour and thirty minutes after 00h00 UTC each day, i.e. at 01h30 UTC and the 4.5 hour offset at $04 \mathrm{~h} 30$ UTC. For six-hour intervals, the error in $\beta^{30}$ is therefore minimized by the selection of data recorded at $01 \mathrm{~h} 30,07 \mathrm{~h} 30,13 \mathrm{~h} 30$ and $19 \mathrm{~h} 30 \mathrm{UTC}$ or $04 \mathrm{~h} 30,10 \mathrm{~h} 30,16 \mathrm{~h} 30$ and $22 \mathrm{~h} 30 \mathrm{UTC}$ each day, rather than at $00 \mathrm{~h} 00,06 \mathrm{~h} 00,12 \mathrm{~h} 00$ and $18 \mathrm{~h} 00 \mathrm{UTC}$. Using only 0.28 $\%$ of the original amount of compliant data, this choice of six-hour intermittency interval data 
allows all wind parameters to be identified with a relative accuracy of better than $2.5 \%$ and 1 $\%$ for a 1.5 hour - and 4.5 hour offset respectively, compared to the $13 \%$ in the case of no offset. The applicability of this observation was also investigated for the NWRAP site Kanas where wind data are acquired as 10 minute records at $20.93 \mathrm{~m}$ AGL and $52.18 \mathrm{~m}$ AGL. The results for Kanas at $20.93 \mathrm{~m}$ AGL for the year 2013 are presented in table 5. The NDRR was $100 \%$.

\section{Table 5}

Offset sensitivity of wind parameters at 20.93 m AGL at Kanas

\begin{tabular}{ccccccccc}
\hline $\begin{array}{c}\text { Offset } \\
\text { [hours] }\end{array}$ & $\begin{array}{c}\overline{\mathrm{u}} \\
{[\mathrm{m} / \mathrm{s}]}\end{array}$ & $\begin{array}{c}\mathrm{S}_{\mathrm{u}} \\
{[\mathrm{m} / \mathrm{s}]}\end{array}$ & $\begin{array}{c}\mathrm{k} \\
{[1]}\end{array}$ & $\begin{array}{c}\Delta \mathrm{k} \\
{[\%]}\end{array}$ & $\begin{array}{c}\mathrm{A} \\
{[\mathrm{m} / \mathrm{s}]}\end{array}$ & $\begin{array}{c}\Delta \mathrm{A} \\
{[\%]}\end{array}$ & $\begin{array}{c}\beta 0 \\
{\left[\mathrm{~m}^{3} / \mathrm{s}^{3}\right]}\end{array}$ & $\begin{array}{c}\Delta \tilde{\mathrm{P}} \\
{[\%]}\end{array}$ \\
\hline & & & & & & & & \\
- & 4.939 & 2.454 & 2.116 & - & 5.577 & - & 108.969 & - \\
1.5 & 4.903 & 2.452 & 2.101 & -0.709 & 5.536 & -0.735 & 107.314 & -1.519 \\
4.5 & 4.950 & 2.408 & 2.166 & 2.363 & 5.589 & 0.215 & 107.364 & -1.473 \\
\hline
\end{tabular}

The errors in table 5 are calculated as per eq. Error! Reference source not found., the reference being the value of the relevant parameter for the ten-minute compliant interval. Comparing $\Delta \tilde{P}$ for the six-hour intermittency interval without offset in fig. 10 with $\Delta \tilde{P}$ indicated in table 5, it is observed that these errors - like in the case of Gobabeb - are also considerably reduced with the introduction of the same offsets as at Gobabeb. The introduction of the indicated offsets at Kanas allows all Weibull parameters to be identified to $1 \%$ to $2.5 \%$ relative accuracy from $2.8 \%$ of the compliant data. In Namibia, the sun rises on average 1 hour and 15 minutes (30 minutes in mid-Winter and 2 hours in mid-Summer) before 06 h00 UTC, so that the 1.5 hour offset after 06h00 UTC occurs on average 2 hours and 45 minutes after sunrise ( 2 hours in mid-Winter and 3 hours and 30 minutes in midSummer). The results for Gobabeb and Kanas suggest that long intermittency interval data can provide even more accurate estimates of Weibull parameters than those indicated in figs. 8 to 11, provided these observations are optimally timed. With the ideal offsets being the same for the two stations, it seems that the optimal timing of observations might be related to the development of thermal activity after sunrise. However, the optimal timing can only be determined from compliant data. As it is unlikely that historic devices would have produced such well-timed data, the observation is probably only of academic interest.

\section{Sensitivity of Weibull parameters to averaging intervals}

For the purposes of evaluating the sensitivity of Weibull parameters to the length of averaging intervals, the moment method described in section 3 was used to identify wind parameters from the one minute records of mean wind speed produced by both NRG\#40C anemometers on the $30 \mathrm{~m}$ mast at Gobabeb during 2013. In this case, however, only days with complete data records were included in the analysis and the net data recovery rate (NDRR) was $95.616 \%$, representing 349 days. The values of these parameters at the two elevations were then used as reference to evaluate the sensitivity of the wind parameters to increasing lengths of averaging interval. The mean wind speeds $\bar{u}_{n, j}$ for these longer averaging intervals of $n$ minutes length are the means of the one minute records $u_{1, j, i}$ of mean wind speed calculated over the longer averaging intervals. The mean wind speed over a single averaging interval $j$ of $n$ minutes is calculated as : 
$\overline{\mathrm{u}}_{\mathrm{n}, \mathrm{j}}=\frac{1}{\mathrm{n}} \sum_{\mathrm{i}=1}^{\mathrm{i}=\mathrm{n}} \mathrm{u}_{1, \mathrm{j}, \mathrm{i}}$

The wind parameters were then identified from all available data records $\bar{u}_{n, j}$ for a range of averaging intervals of length $n$ minutes, with $n$ ranging between 10 - and 1440 minutes. Table 6 presents the results of the averaging interval sensitivity analysis for the data of the NRG\#40C anemometer at $27.53 \mathrm{~m} \mathrm{AGL}$ at Gobabeb. The mean wind speed is $4.363 \mathrm{~m} / \mathrm{s}$ for all averaging intervals.

\section{Table 6}

Averaging interval sensitivity of wind parameters at 27.53 m AGL at Gobabeb

\begin{tabular}{|c|c|c|c|c|c|c|c|c|}
\hline $\begin{array}{c}\text { Interval } \\
\text { [min] }\end{array}$ & $\begin{array}{c}\mathrm{s}_{\mathrm{u}} \\
{[\mathrm{m} / \mathrm{s}]}\end{array}$ & $\begin{array}{c}\mathrm{k} \\
{[1]}\end{array}$ & $\begin{array}{l}\Delta \mathrm{k} \\
{[\%]}\end{array}$ & $\begin{array}{c}\mathrm{A} \\
{[\mathrm{m} / \mathrm{s}]}\end{array}$ & $\begin{array}{l}\Delta \mathrm{A} \\
{[\%]}\end{array}$ & $\begin{array}{c}\beta 0 \\
{\left[\mathrm{~m}^{3} / \mathrm{s}^{3}\right]}\end{array}$ & $\begin{array}{l}\Delta \tilde{\mathrm{P}} \\
{[\%]}\end{array}$ & $\begin{array}{c}\text { \# Data } \\
\text { [1] }\end{array}$ \\
\hline 1 & 2.550 & 1.768 & - & 4.901 & - & 90.737 & - & 502560 \\
\hline 10 & 2.495 & 1.810 & 2.432 & 4.907 & 0.121 & 88.236 & -2.756 & 50256 \\
\hline 20 & 2.474 & 1.828 & 3.389 & 4.909 & 0.163 & 87.295 & -3.793 & 25128 \\
\hline 30 & 2.465 & 1.842 & 4.206 & 4.911 & 0.197 & 86.524 & -4.643 & 16752 \\
\hline 60 & 2.409 & 1.882 & 6.449 & 4.915 & 0.278 & 84.512 & -6.860 & 8376 \\
\hline 120 & 2.328 & 1.955 & 10.610 & 4.921 & 0.391 & 81.145 & -10.571 & 4188 \\
\hline 180 & 2.247 & 2.033 & 15.020 & 4.924 & 0.466 & 78.020 & -14.015 & 2792 \\
\hline 240 & 2.170 & 2.114 & 19.590 & 4.926 & 0.503 & 75.183 & -17.142 & 2094 \\
\hline 360 & 2.062 & 2.238 & 26.602 & 4.926 & 0.499 & 71.471 & -21.232 & 1396 \\
\hline 480 & 1.836 & 2.547 & 44.064 & 4.915 & 0.274 & 64.635 & -28.767 & 1047 \\
\hline 720 & 1.747 & 2.692 & 52.279 & 4.906 & 0.104 & 62.244 & -31.401 & 698 \\
\hline 1440 & 1.314 & 3.699 & 109.241 & 4.834 & -1.365 & 52.789 & -41.822 & 349 \\
\hline
\end{tabular}




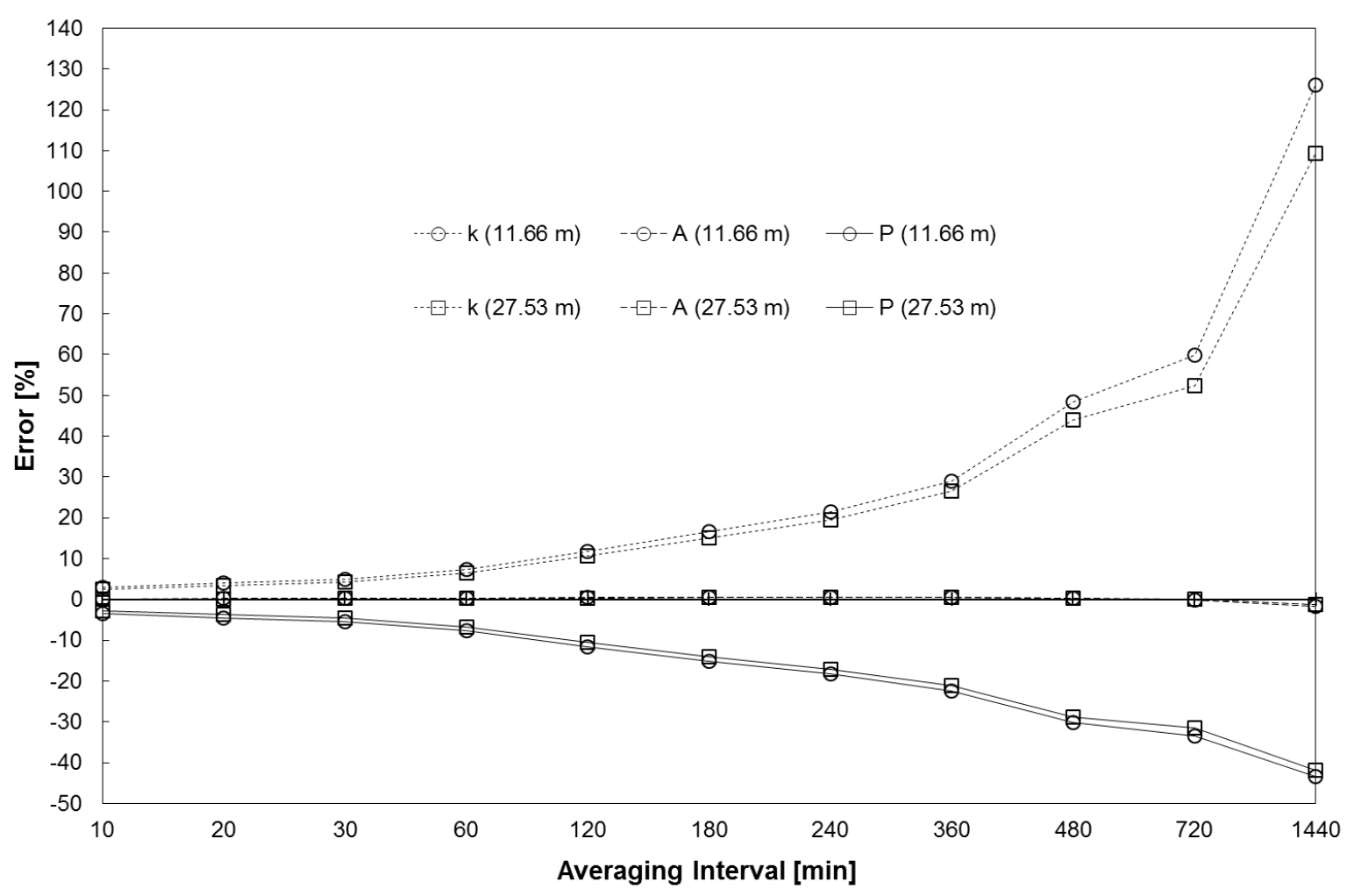

Fig. 14. Averaging interval errors of wind parameters at Gobabeb

\# Data in table 6 is the total number of synthesized data records $\bar{u}_{n, j}$ from which the Weibull parameters were derived for the indicated averaging intervals of length $\mathrm{n}$ minutes. From table 6 it is observed that Weibull parameter $A$ is much less sensitive to the length of the averaging interval than $\mathrm{k}$ and $\beta^{6}$ and that $A$ identifies with an accuracy of $0.5 \%$ or better for all averaging intervals of 12 hours or less. The errors in $k$ and $\beta^{6}$ are always positive and negative respectively and quickly grow to $10 \%$ or more for averaging intervals of 2 hours or longer. For a typical automatic weather station with an averaging interval of 60 minutes the errors in $\mathrm{k}$ and $\mathrm{B}^{\circ}$ approach $7 \%$. Fig. 14 is a chart of the averaging interval errors in $\mathrm{k}, \mathrm{A}$ and $\beta^{6}$ at both elevations at Gobabeb.

\section{Discussion and conclusion}

Sets of intermittency - and averaging interval deficient data were synthesized from four annual data sets produced by DAS that closely comply with international standards of wind measurement such as IEC 61400-12-1:2005(E) and IEA Recommendation 11. Using the moment method, annual Weibull parameters were identified for all the data sets and compared. It was demonstrated that the Weibull parameters $\mathrm{k}, \mathrm{A}$ and $\beta^{\circ}$ identified from intermittency interval deficient data synthesized from compliant data measured at different elevations at four widely dispersed wind measurement stations in Southern Africa are remarkably insensitive to the length of intermittency intervals for intervals ranging between ten minutes and six hours long. The same parameters were however found to be comparatively sensitive to the length of averaging intervals as demonstrated in the case of Gobabeb for which the relative error in $\beta^{30}$ is an order of magnitude larger for one-hour averaging intervals than for one-hour intermittency intervals.

In all cases it was found that all Weibull parameters could be identified with a relative accuracy of $1 \%$ for intermittency intervals of up to one hour. It was further shown that the relative accuracy of the Weibull parameters in general deteriorates with increasing length of 
intermittency interval, with relative accuracies of $\beta$ being between $2 \%$ and $13 \%$ for six hour intervals starting at $06 \mathrm{~h} 00$ UTC. For an optimum selection of six-hour intermittency intervals, it was found that the error in the identified parameters could potentially be further reduced. It was also demonstrated in the case of Gobabeb that Weibull parameter A is virtually independent of the length of averaging interval for averaging intervals of half a day or less and that it can be identified with an accuracy of $2 \%$ or better for averaging intervals of one full day or less. The relative independence of Weibull parameter A on averaging interval can be ascribed to the independence of mean wind speed on averaging interval and the almost constant ratio between mean wind speed and Weibull parameter $A$ for large values of $k$ as shown in fig. 15, which is a chart of eqs. (0) and (0).

From fig. 15 it may be observed that there is virtually a constant ratio between mean wind speed and Weibull parameter A for values of Weibull parameter k between 1.75 and 3 , the typical values for $\mathrm{k}$ encountered in table 6 . The constant ratio is approximately 1.125 . In contrast to the insensitivity of Weibull parameter A to averaging interval, Weibull parameters $\mathrm{k}$ and $\beta^{\beta}$ are very sensitive to averaging interval, the reason being that longer averaging intervals reduce the variability of the wind and thus the variance - and standard deviation of wind speed as is also evident from fig. 15 read together with the range of values of $k$ as shown in table 6 . A case in point is the $3.5 \%$ relative error in these parameters for the relatively short ten-minute averaging interval as specified in IEC 61400-12-1:2005(E) and also employed in NWRAP. This error is larger than that for the same parameters identified from four-hour intermittency interval data. For averaging intervals of one hour which is typical of general purpose AWS, the accuracy in Weibull parameters $k$ and $\beta$ o deteriorate to approximately $8 \%$, which is comparable with the error in the same parameters identified from six-hour intermittency interval data.

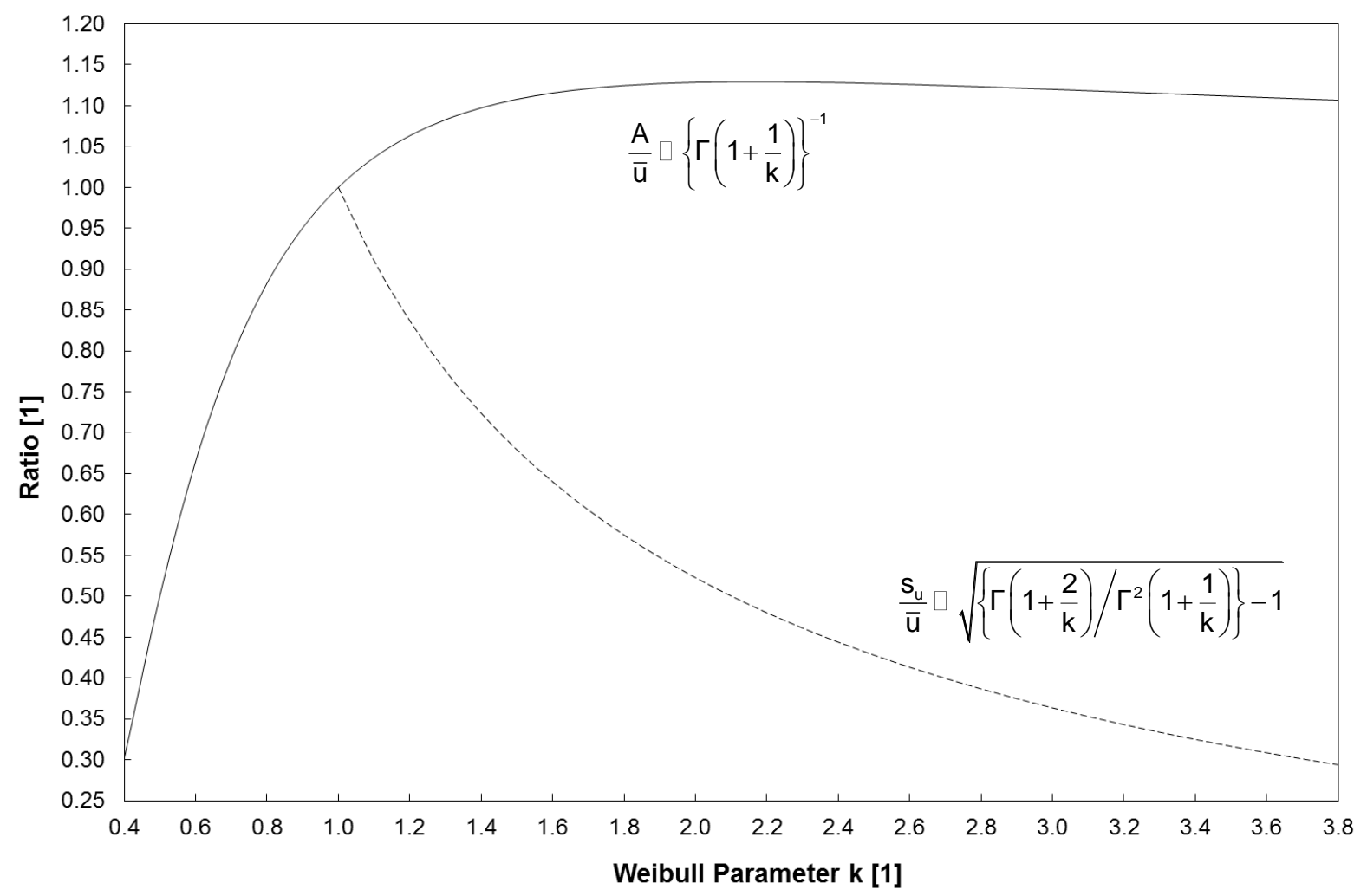

Fig. 15. Parameter ratios as a function of Weibull parameter $\mathrm{k}$ 


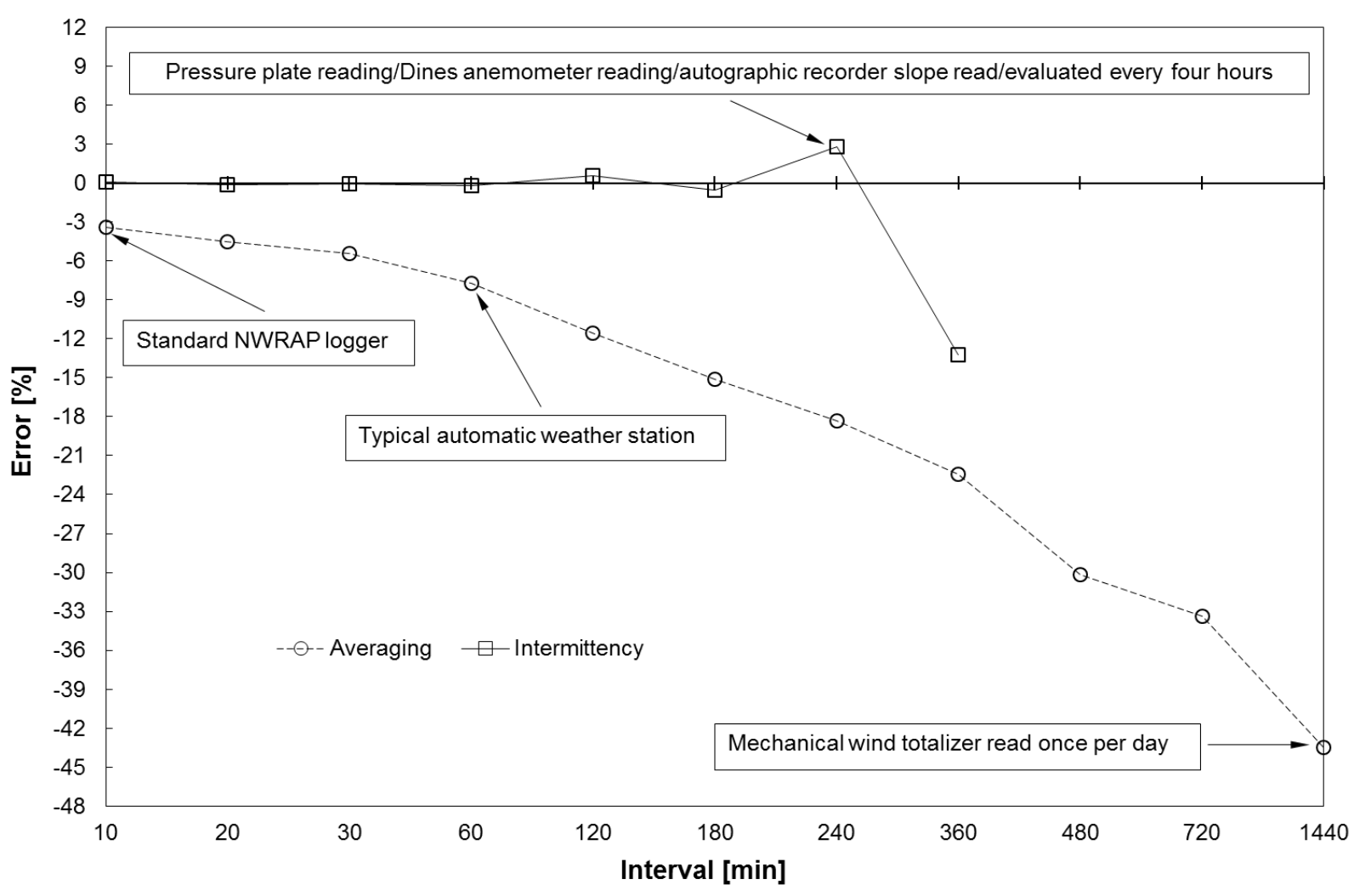

Fig. 16. Error in air density normalized mean wind power density at Gobabeb

The findings of the sensitivity analyses suggest that certain interval deficient data produced by DAS of varying technological sophistication could potentially be employed in the identification of relatively accurate Weibull parameters provided the dynamic characteristics and accuracy of the DAS that produced such data are comparable with those of compliant DAS. The decision on which data to use, is determined by the desired accuracy of the Weibull parameters. Fig. 16 puts the relative error in air density normalized mean wind power density $\beta^{30}$ as identified from data produced by the indicated DAS at Gobabeb into perspective. The less sophisticated mechanical wind DAS technologies identified in fig. 16 are those that have historically been in extensive use in Namibia as from the 1940s until the early 1990s when they were replaced or augmented by electronic automatic weather stations. Assuming that these technologies have dynamic responses and accuracies similar to the IEC 61400-12-1:2005(E) compliant systems, fig. 16 and the previous discussion suggest that in terms of their ability to produce all wind parameters with a relative accuracy of $5 \%$ or better, the indicated data of the following historic DAS may potentially be successfully employed in wind assessments :

- four-hourly - or better spot values of continuous wind speed data produced by Dines anemometers

- four-hourly - or better spot evaluations of slopes of continuous wind run traces produced by autographic wind recorders

- four-hourly - or better values of spot observations of wind speed produced by pressure plate indicators

If an accuracy of $8 \%$ or better is acceptable, the analysis for Gobabeb suggests that hourly - or better averages of wind speed produced by automatic weather stations may also be considered. Inasmuch as much of the data produced by the historic systems may never have been digitized and the likelihood that their dynamic response and absolute accuracy may in fact not be comparable with those of compliant systems, automatic weather station 
data with averaging intervals of one hour or better probably represent the most cost-effective option. However, employing interval deficient data produced by historic devices may be an interesting prospective for analysts who are interested in investigating the influence of global warming on wind regimes, provided the relationships between the dynamic characteristics of historic devices and modern DAS could be established.

The findings of the study also suggest that accurate Weibull parameters can possibly be determined from wind data provided by anemometers that are operational for only one minute per hour. This finding suggests that anemometer life can be considerably extended and logger data storage capability significantly reduced.

\section{Acknowledgements}

The authors would like to thank the Council for Scientific and Industrial Research of South Africa for availing the wind data for the Noupoort station of the Wind Atlas of South Africa project of the Department of Energy of the Republic of South Africa. The data were downloaded free of charge from www.wasa.csir.co.za.

The authors would also like to thank Dr Gillian Maggs-Kölling, executive director of Gobabeb Research and Training Centre and Dr Roland Vogt of the Institute of Meteorology, Climatology and Remote Sensing of the University of Basel for their contributions to - and interest in this study.

\section{References}

1. IEC. International Standard - IEC 61400-12-1 - Wind turbines - Part 12-1 : Power performance measurements of electricity producing wind turbines. 1. Geneva : IEC, 2005.

2. Weibull-k Revisited: "Tall” Profiles and Height Variation of Wind Statistics. Kelly, M, Troen, I and Jørgensen, H E. s.I. : Springer, 2014, Boundary Layer Meteorology, Vol. 152, pp. 107 - 124.

3. A Note on Vertical Extrapolation Formulas for Weibull Velocity Distribution Parameters. Doran, J C and Verholek, M G. s.I. : American Meteorological Society, 1978, Journal of Applied Meteorology, Vol. 17, pp. 410 - 412.

4. Statistical study of the influence of the data sampling interval on the estimation of wind turbine energy. Abbes, D, et al., et al. Granada : European Association for the Development of Renewable Energies, Environment and Power Quality (EA4EPQ), 2010. International Conference on Renewable Energies and Power Quality (ICREPQ'10).

5. Influence of the data sampling interval in the estimation of the parameters of the Weibull wind speed probability density distribution: a case study. Ramírez, $P$ and Carta, J A. s.I. : Elsevier, 2005, Energy Conversion and Management, Vol. 46, pp. 2419 2438.

6. The Autocorrelation of Hourly Wind Speed Observations. Brett, A C and Tuller, S E. s.l. : American Meteorological Society, June 1991, Journal of Applied Meteorology, Vol. 30, pp. 823 - 833. 
7. The effects of disjunct sampling and averaging time on maximum mean wind speeds. Larsén, X G and Mann, J. s.I. : Elsevier, 2006, Journal of Wind Engineering and Industrial Aerodynamics, Vol. 94, pp. 581 - 602.

8. The Influence of Sampling and Filtering on Measured Wind Gusts. Beljaars, A C M. s.l. : American Meteorological Society, December 1987, Journal of Atmospheric and Oceanic Technology, Vol. 4, pp. 613 - 626.

9. Effective Number of Observations and Unbiased Estimators of Variance for Autocorrelated Data - an Overview. Zięba, A. 1, s.l. : Polish Academy of Sciences, 2010, Metrology and Measurement Systems, Vol. XVII, pp. 3 - 16.

10. Review of Weibull Statistics for Estimation of Wind Speed Distributions. Conradsen, K, Nielsen, L B and Prahm, L P. s.I. : American Meteorological Society, August 1984, Journal of Climate and Applied Meteorology, Vol. 23, pp. 1173 - 1183.

11. Basic meteorological stations as wind data source: A mesoscalar test. AgüeraPérez , A, et al., et al. s.l. : Elsevier, 2012, Journal of Wind Engineering and Industrial Aerodynamics, Vols. 107 - 108, pp. 48 - 56.

12. Strohbach, B. The SASSCAL/MAWF Weather Stations Network in Namibia Overview of equipment and data transfer. School of Natural Resources and Spatial Sciences, Namibia University of Science and Technology. unpublished results.

13. SASSCAL. SASSCAL - Southern African Science Service Centre for Climate Change and Adaptive Land Management. [Online] [Cited: 4 September 2016.] http://www.sasscal.org/?lang=en.

14. The Response of the Dines Anemometer to Gusts and Comparisons with Cup Anemometers. Miller, C, et al., et al. s.I. : American Meteorological Society, July 2013, Journal of Atmospheric and Oceanic Technology, Vol. 30, pp. 1320 - 1336.

15. Pedersen, T F, et al., et al. ACCUWIND - Accurate Wind Speed Measurements in Wind Energy - Summary Report. Risø National Laboratory. Roskilde : Risø National Laboratory, 2006. ISBN 87-550-3526-4.

16. The Helicoid Anemometer A Long Neglected but Valuable Anemometer. Gill, G C. s.l. : Canadian Meteorological Society, 1973, Atmosphere, Vol. 11 : 4, pp. 145 - 155.

17. Baynton, H W. Errors in Wind Run Estimates from Rotational Anemometers. Bulletin American Meteorological Society. September 1976, Vol. 57, 9, pp. 1127 - 1130.

18. Dahlberg, J-Å, Pedersen, T F and Busche, P. ACCUWIND - Methods for Classification of Cup Anemometers. Roskilde : Risø National Laboratory, 2006. ISBN 87-550-3514-0.

19. Williams, D E and Siepker, E B J. Design, Construction and Calibration of an Electronic Pressure Plate Wind Indicator. Department of Mechanical - and Marine Engineering, Namibia University of Science and Technology. unpublished results.

20. R, Vogt. Comparison of Wind Run and Cup Anemometer Measurements. unpublished results.

21. Experimental study of the effect of tower shadow on anemometer readings. Orlando, S, Bale, A and Johnson, D A. s.I. : Elsevier, 2011, Journal of Wind Engineering and Industrial Aerodynamics, Vol. 99, pp. 1 - 6.

22. A Model for the Correction of Surface Wind Data for Sheltering by Upwind Obstacles. Taylor, P A and Salmon, J R. s.I. : American Meteorological Society, November 1993, Journal of Applied Meteorology, Vol. 32, pp. 1683 - 1694.

23. Proposal for a general method to derive mast corrections in wind speed measurements based on intrinsic geometry parameters. Cañadillas, B and Neumann, T. Copenhagen : European Wind Energy Association, 2012. p. PO 632. 
24. Effects of Tower Shadowing on Anemometer Data. Lubitz, W D. San Juan : International Association for Wind Engineering, 2009. 11th Americas Conference on Wind Engineering.

25. Siepker, E B J and Harms, T M. The National Wind Resource Assessment Project of Namibia - Description and Observed Wind Climates. Department of Mechanical - and Marine Engineering, Namibia University of Science and Technology. unpublished results.

26. Otto, A. WASA The Wind Atlas for South Africa Project Phase 1. Sandton : South African National Energy Development Institute, 2015. ISBN: 978-0-620-63781-7.

27. Gobabeb - 50 years of Namib Desert research. Henschel, J R and Lancaster, N. s.I. : Elsevier, 2013, Journal of Arid Environments, Vol. 93, pp. 1 - 6.

28. Pedersen , B M, et al., et al. Expert Group Study on Recommended Practices for Wind Turbine Testing and Evaluation 11. Wind Speed Measurement and Use of Cup Anemometry. [ed.] R S Hunter. s.I. : International Energy Agency, 1999.

29. Centre for Renewable Energy Sources. WindRose - A wind data analysis tool - User's Guide. Pikermi : Centre for Renewable Energy Sources, 2009.

30. Troen, I and Lundtang Petersen, E. European Wind Atlas. Roskilde : Risø National Laboratory, 1989. ISBN 87-550-1482-8.

31. A new method to estimate Weibull parameters for wind energy applications. Akdağ, S A and Dinler, A. s.I. : Elsevier, 2009, Energy Conversion and Management, Vol. 50, pp. 1761 - 1766.

32. Comparison of seven numerical methods for determining Weibull parameters for wind energy generation in the northeast region of Brazil. Rocha, P A C, et al., et al. s.I. : Elsevier, 2011, Applied Energy, Vol. 89, pp. 395 - 400.

\footnotetext{
a The work is funded by Ministry of Foreign Affairs of Denmark, Ministry of Foreign Affairs of Finland, United Kingdom Department for International Development, Austrian Development Agency and Namibia Power Corporation. In-kind support is provided by University of Basel and Namibia University of Science and Technology.

b Corresponding author, Department of Mechanical - and Marine Engineering, Namibia University of Science and Technology, Private Bag 13388, Windhoek, Namibia, E-mail address : bsiepker@nust.na, Tel : +264 61207 2058, Fax : +264 612072142

${ }^{c}$ Department of Mechanical - and Mechatronic Engineering, Stellenbosch University, Private Bag X1, Matieland, 7602, Stellenbosch, South Africa, E-mail address : tmh@sun.ac.za
} 